\title{
DISTRIBUTION OF THE LEGALLY PROTECTED LICHEN SPECIES SOLORINA SACCATA IN HUNGARY
}

\author{
Mónika Sinigla ${ }^{1}$, László Lő Kös ${ }^{2}$, Katalin MolNÁR ${ }^{3}$, Csaba NÉMETH ${ }^{4}$ \\ and Edit FARKAS ${ }^{4}$ \\ ${ }^{1}$ Bakony Museum of the Hungarian Natural History Museum, \\ H-8420 Zirc, Rákóczi tér 3-5. Hungary; sinigla.monika@nbmus.hu \\ ${ }^{2}$ Department of Botany, Hungarian Natural History Museum, \\ H-1476 Budapest, Pf. 222. Hungary; lokos.laszlo@nhmus.hu \\ ${ }^{3}$ Mylan Hungary Ltd., 2900 Komárom, Mylan u. 1. Hungary \\ ${ }^{4}$ Institute of Ecology and Botany, MTA Centre for Ecological Research, Hungarian Academy of \\ Sciences, H-2163 Vácrátót, Alkotmány u. 2-4.Hungary; farkas.edit@okologia.mta.bu
}

Sinigla, M., Lőkös, L., Molnár, K., Németh, Cs. \& Farkas, E. (2018): Distribution of the legally protected lichen species Solorina saccata in Hungary. - Studia bot. hung. 49(1): 47-70.

\begin{abstract}
Solorina saccata received endangered status in the Hungarian lichen red list in 1997, and legal protection in Hungary in 2013. Based on its $c a 200$, old and recent, herbarium and literature records ca 100 localities from the Aggtelek karst (1), Bakony Mts (29), Balaton Uplands (5), Buda Mts (8), Bükk Mts (7), Gerecse Mts (6), Keszthely Mts (10), Kőszeg Mts (2), Pilis Mts (2) and Vértes Mts (30) are registered. These currently known occurrence data are presented on a distribution map. Although it seems to be common at present in its potential habitats in the Transdanubian Mountain Range, these habitats are considered to be under real risk of habitat destruction and fragmentation parallel to the global tendency of population shrinkage of the species in Europe. In addition, habitat preferences and population dynamical conditions of Solorina saccata, necessary also for conservational purposes, are still insufficiently known. Maintaining the current condition of its habitats is crucial for the effective protection.
\end{abstract}

Key words: Hungary, legally protected, lichen-forming fungi, Solorina saccata

\section{INTRODUCTION}

Solorina saccata (L.) Ach. (Peltigeraceae, Ascomycota) is a rather conspicuous and characteristic foliose lichen species. Thalli usually form rosettes (2-5 $\mathrm{cm}$ in diam.) or irregular aggregations. Lobes are flat, round $(10-20 \mathrm{~mm})$, broad and short; upper surface greyish-brownish in dry and bright apple-green in wet conditions (Fig. 1), smooth or white pruinose; lower surface whitish to tan, tomentose; rhizines sparse, long, white. Photobionts are green algae (Coccomyxa solorina-saccatae) together with cyanobacteria (Nostoc) in internal cephalodia. Apothecia are common, unmargined, dark red-brown to brown-black, 2-6 $\mathrm{mm}$ in diameter, sessile or depressed in the upper side of the lobes. Asci usually con- 
tain 4 brown, two-celled, ellipsoidal to fusiform, Peltigera-type ascospores, 30-60 $\times 18-28 \mu \mathrm{m}$. Chemical substances are unknown. (Verseghy 1994, VitikaineN 2007, WiRTH et al. 2013).

Solorina saccata is a widespread species, distributed mostly in circumpolar, cool-temperate to arctic alpine and boreal areas throughout Europe, Asia and North America (e.g., Albania: HAfellner 2007; Austria: HAfEllneR and TürK 2001, 2016; Belgium: Diederich and SÉrusiaux 2000; Bosnia and Herzegovina: BILOVITZ and MAYRHOFER 2011; Bulgaria: MAYRHOFER et al. 2005; Czech Republic: LišKa et al. 2008; Denmark: Søchting and Alstrup 2008; Estonia: RANDLANe and SaAg 1999; Finland: Vitikainen 2007, Stenroos et al. 2016; France: Roux et al. 2017; Germany: WiRTH et al. 2013; Great Britain; SMITH et al. 2009; Ireland: SEAWARD 1984, 1994, SMITH et al. 2009; Italy: Nimis 2016; Kosovo: MAYrhofer et al. 2016; Latvia: Abolina et al. 2015; Lithuania: MotiejūNAIté 2017; Macedonia: MAYRHOFER et al. 2013; Montenegro: KNEŽEVIĆ and MAYRHOFER 2009; Netherlands: Aptroot et al. 2004; Norway: SANTESSON et al. 2004; Poland: FaŁtynowiCZ and Kossowska 2016; Portugal: Llimona and HLAdUN 2001, Burgaz and Martínez 1998, 2003; Romania: Ciurchea 2004; Serbia: SAvić and Tibell 2006; Slovakia: Guttová et al. 2013; Slovenia: PrÜgger et al. 2000; Spain: Llimona and Hladun 2001, Burgaz and Martínez 1998, 2003; Sweden: SANTESSON et al. 2004; Switzerland: CleRC and TRUONG 2012; Ukraine: KONDRATYUK et al. 1998, 1999; etc.). It is regarded as "least concern" species in those countries with numerous known locality records and potential habitats (e.g. Finland (STENroos et al. 2016), Great Britain and Ireland (Woods and Coppins 2012), Norway (2017, https://artsdatabanken.no/Rodliste), Sweden (2017, http:// artfakta.artdatabanken.se/), Switzerland (SCHEIDEgGer and Clerc 2002). On the other hand it is evaluated in various red list categories in the following countries where it is rather rare, e.g. "extinct" in the Netherlands (Арт Root et al. 2004) and in Lithuania (MotiejūNaité 2017); "endangered" in the Czech Republic (LišKa et al. 2008), in Hungary (Löкös and Tóтн 1997), and in Latvia (AвоLINA et al. 2015); "strongly threatened" in Germany (WIRTH et al. 2011); "threatened" in Austria (out of the Alps) (TüRK and HAFELLNER 1999); "near threatened" in Estonia (RAndlane et al. 2008)); "vulnerable" in Denmark (Søchting and AlsTRUP 2008), in Poland (Mirek et al. 2006), and in Ukraine (Didukh 2009). It is legally protected in Estonia and in Hungary.

Macroclimate does not play an obvious role in its distribution; it can grow from sea level to high mountain elevations. However, a reduced tendency of its global distribution has been detected at first in Britain and later in whole Europe (Gilbert 1975).

Solorina saccata has been considered as a character species in various cryptogamic and grassland associations. KLEMENT (1955) classified S. saccata as 

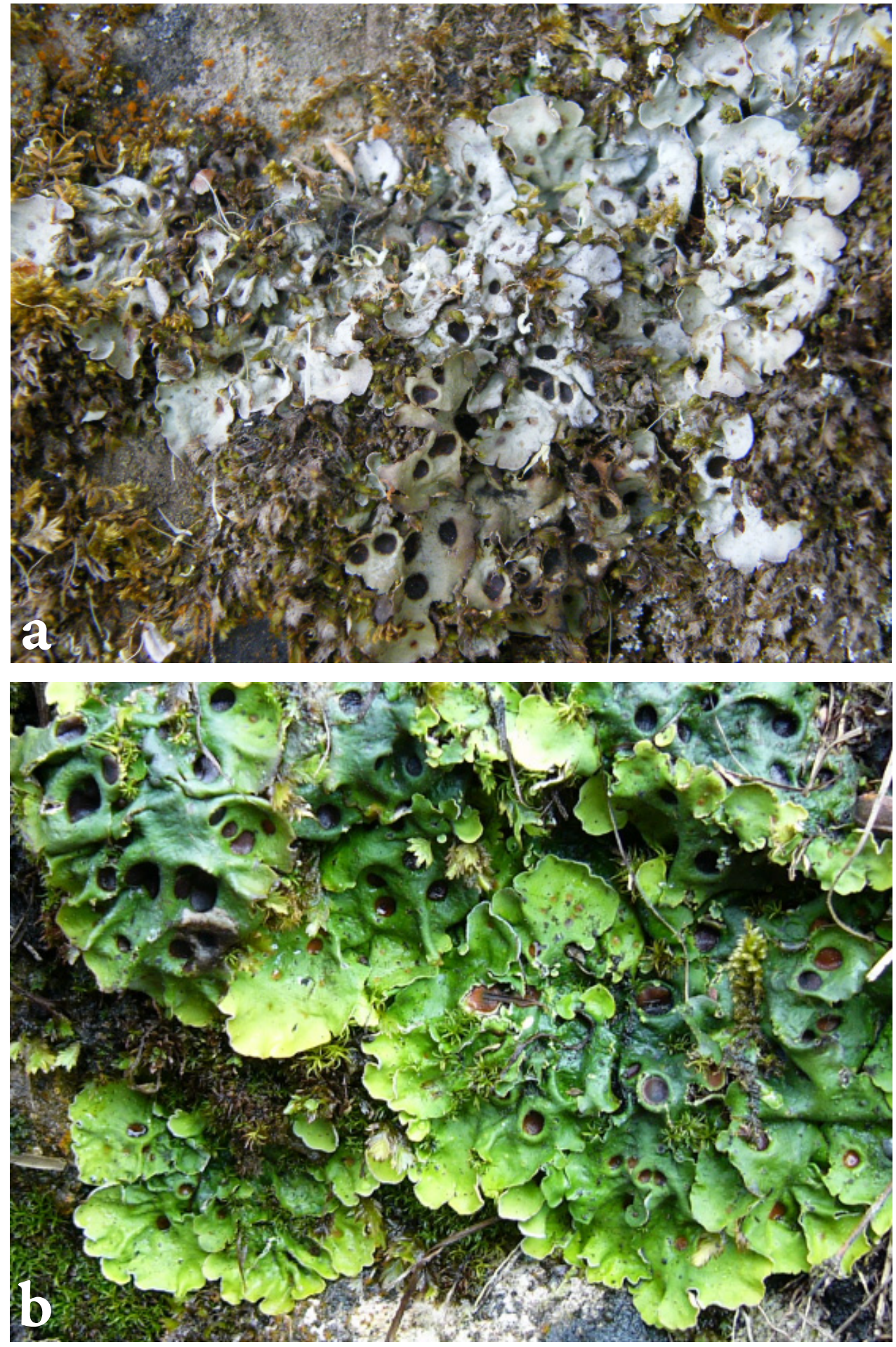

Fig. 1. Solorina saccata in dry (a) and wet (b) conditions (photo: (a) Sinigla, M., (b) Németh Cs.). 
phytosociological order and class character species in the lichen association Cladonietum symphycarpiae Doppelbaur 1950. The lichen association Solorinetum saccatae was recognised by BESCHEL (1958) as an independent lichen association, but this syntaxon has not been used hereafter. Gallé regarded it as a member of the terricolous Fulgensia fulgens synusium (GALLÉ 1977), and in his Hungarian system he included S. octospora in the Cladonietum symphycarpiae association instead of $S$. saccata.

Following Reimers's concept (REIMERS 1940) S. saccata was treated in the bryophyte association Solorino saccatae-Distichietum capillacei Reimers 1940 by MARSTALler $(1994,1996)$.

It was also recorded in Hungarian phytosociological studies in the plant associations Festuco-Brometum erecti in the Bakony Mts (FeKETE et al. 1961), and in Seslerietum budensis and Festuco-Brometum erecti archimatricum in the Buda Mts (Simon et al. 1976, Zólyomi 1936, 1950, 1958).

Solorina saccata was ranked as an endangered species in the red list of the Hungarian lichen-forming fungi (Löкӧs and То́тн 1997), because of its rare and special occurrence in Hungary. Solorina saccata is the only species of its genus in Hungary. It received legal protection in 2013 (MK 2013 as Solorina saccata ("pettyegetett tárcsalapony")), due to first of all its rarity. Although its conspicuous, really nice, aesthetic outlook makes it as a potential target of over-collecting, the main threatening factor of the protection is the possible risk of damage, destruction or fragmentation of its habitats e.g. by stone mining, motocross activities, unfavourable forestry management, excessive wildlife, or other disturbance.

The aim of our study was to give an overview on the Hungarian distribution of Solorina saccata based on all available historical and recently found specimens and literature sources.

\section{MATERIAL AND METHODS}

A total of 190 specimens were involved in our study deposited in the following Hungarian herbaria: BP, BMCRY, EGR, JPU, SAMU, SZE, VBI, hb. Németh (abbreviations mainly follow the Index Herbariorum online; THIERs 2014).

Literature data of MARstaller $(1994,1996)$ from the Buda and Pilis Mts, and those of Solymosi $(1975,1976,1979)$ from the Gerecse Mts were considered as doubtful records due to the lack of available vouchers. Following a revision on the Hungarian specimens/literature records of Solorina bispora and S. octospora these species have been excluded from the Hungarian lichen checklist until their confirmation.

The distribution map (Fig. 2) was constructed by the computer program for geographical information system, QGIS 2.18 (Las Palmas, 2017), where grid cells 
of $5 \mathrm{~km} \times 6 \mathrm{~km}$ follow the Central European mapping system (cf. NiKLFELD 1971). Since 2002 locality data have been measured by Garmin GPS devices (WGS84).

\section{RESULTS}

\section{List of localities}

Aggtelek karst - Hungary, Borsod-Abaúj-Zemplén County. Aggtelek karst. Bódvarákó, northern slope of Mt Esztramos, among mossy calcareous rocks in a rocky scrubland habitat. Lat.: $48.518114^{\circ} \mathrm{N}$; Long.: $20.749145^{\circ} \mathrm{E}$; Alt.: $300 \mathrm{~m}$ a.s.l. Leg.: Lőkös, L. and Somlyay, L., 17.04.1998 [BP 96277] [Lő Kös 2009].

Bakony Mts - Mt. Bakony: pr. Bakonybél, in m. "Fehérkő", ad terram. Leg.: Verseghy, K., 1965.07.03. [BMCRY 002200, BP 73031] [VERSEGHY 1973]. Hungary. Veszprém County, Bakony Mts: Mt Fehér-kő ca 4 km SSE of Bakonybél. Lat.: $47.215861^{\circ} \mathrm{N}$; Long.: $17.738825^{\circ} \mathrm{E}$; Alt. $400 \mathrm{~m}$ a.s.l. On calcareous soil among shaded, calcareous rocks. Leg.: Lőkös, L. and Farkas, E., 10.07.1993 [BP 96262]. - Bakony, Veszprém megye, Hárskút, Fehér-kő, É-i kitettségű árnyas mészkőszikla vékony humuszrétegén. É.sz.: $47.21548^{\circ}$; K.h.: $17.73992^{\circ}$; Tszf.m.: kb. 418 m (GPS 2066). Leg.: Németh, Cs., 2007.IV.6. [BP 92941]. - Hungary. Veszprém County, Bakony Mts: Mt Hegyes-kő ca $2.5 \mathrm{~km}$ SSE of Bakonybél. Lat.: 47.230954 ${ }^{\circ} \mathrm{N}$; Long.: $17.738179^{\circ} \mathrm{E}$; Alt.: $310 \mathrm{~m}$ a.s.l. On calcareous soil among

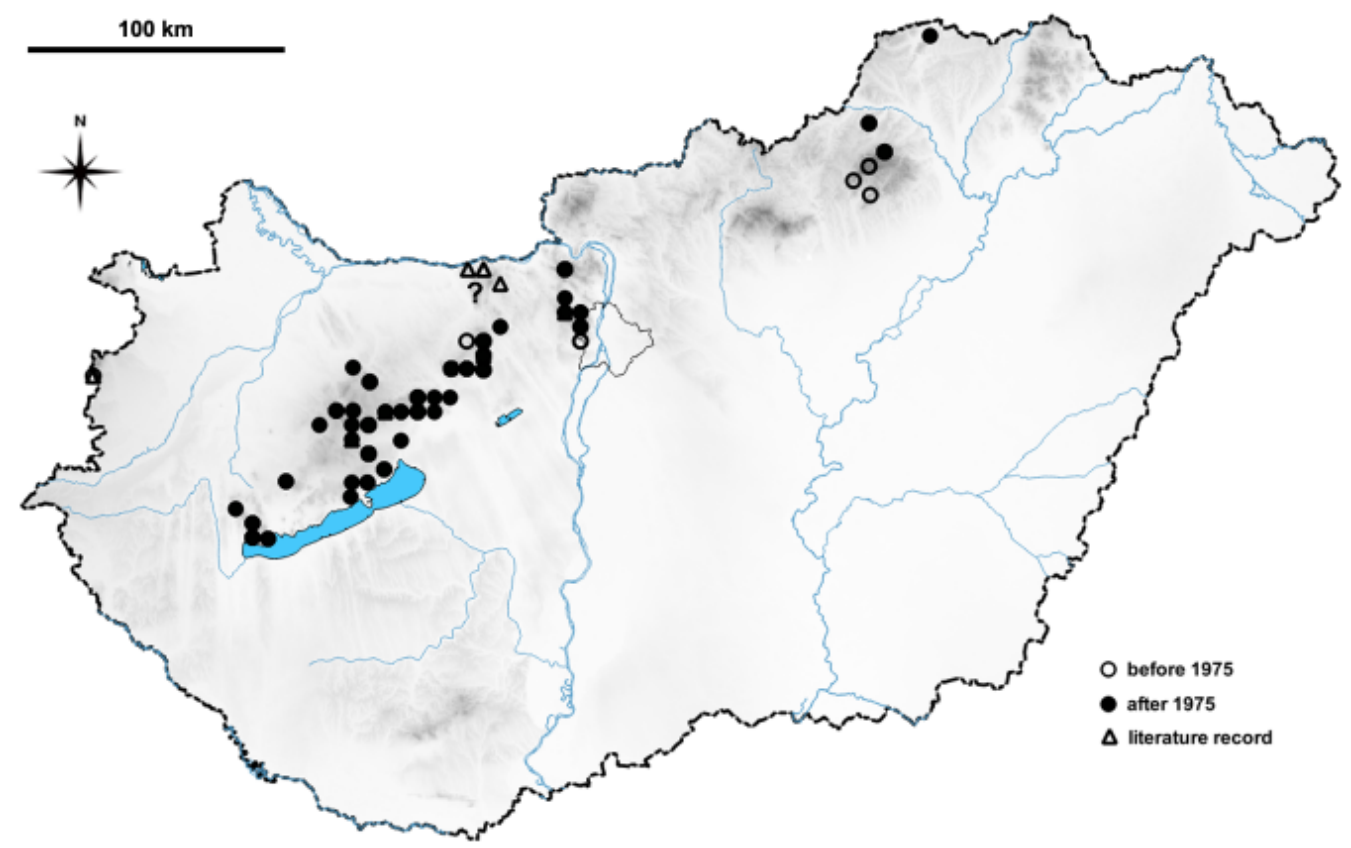

Fig. 2. Distribution map of Solorina saccata in Hungary (? = unconfirmed, doubtful localities). 
shaded, calcareous rocks. Leg.: Lőkös, L. and Farkas, E., 10.07.1993 [BP 96261]. - Bakony, Veszprém megye, Bakonybél, Hegyes-kő, É-i kitettségü árnyas mészkőszikla vékony humuszrétegén. É.sz.: $47.23079^{\circ}$; K.h.: $17.73791^{\circ}$; Tszf.m.: kb. 326 m (GPS 2065). Leg.: Németh, Cs., 2007.IV.6. [BP 92935]. - Bakony, Veszprém megye, Bakonybél, Kertes-kői-szurdok (Oltár-kő), É-i kitettségü árnyas mészkő-

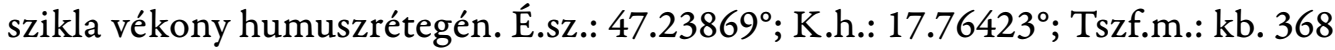
m (GPS 2063). Leg.: Németh, Cs., 2007.IV.6. [BP 92936]. - Bakony, Veszprém megye, Bakonybél, Kertes-kői-szurdok (Oltár-kő), É-i kitettségü árnyas mészkő-

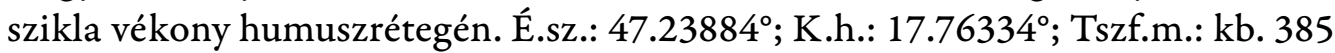
m (GPS 2064). Leg.: Németh, Cs., 2007.IV.6. [BP 92937]. - Comit. Veszprém. In rupibus calcar. silvat. "Ördögárok", pr. Bakonyoszlop. Alt. s. met. ca: 3-400. Leg.: Boros, Á., 1938.03.25. [EGR 5439]. - Bakony, Veszprém megye, Bakonyoszlop, Ördög-árok, északi kitettségben, árnyas mészkősziklán. É.sz.: $47.33120^{\circ}$; K.h.: 17.91334º Tszf.m.: kb. 327 m (GPS 3495/7; 1/1). Leg.: Németh, Cs., 2011.01.09. [BP 94054]. - Bakony, Veszprém megye, Bakonyszentlászló, Alsó-Cuh a szurdok, É-i kitettségü mészkőszikla vékony humuszrétegén. É.sz.: 47.37668; K.h.: 17.82805'; Tszf.m.: kb. 262 m (GPS 2060). Leg.: Németh, Cs., 2007.III.31. [BP 92938]. - Comit. Veszprém. In rupibus calc. vallis Cuhavölgy prope Csesznek. Alt. s. met. ca: 350 m. Leg.: Boros, Á., 1928.06.07. [BP 36732, EGR 5629]. - Bakony: Eplény: Tobán-hegy. [Polgár 1933]. - Bakony, Veszprém megye, Hajmás-

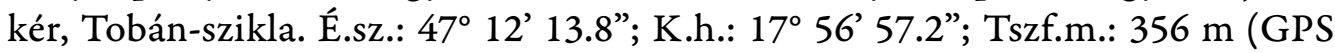
129/2). Leg.: Németh, Cs., 2006.XII.30. [BP 92940]. - Comit. Veszprém. In rupibus calcar. sept. silvat. vallis rivi Kövesd-patak prope Farkasgyepü. Alt. cca: 300 m. s. m. Leg.: Boros, Á., 1951.02.18. [BP 50552]. - Bakony, Veszprém megye, Farkasgyepü, Köves-patak-völgye, árnyas konglomerátum sziklán. É.sz.: 47.19159; K.h.: 17.60767 ${ }^{\circ}$ Tszf.m.: kb. 315 m (GPS 3612/2; 1/1). Leg.: Németh, Cs., 2011.04.16. [BP 94055]. - Bakony: Fehérvárcsurgó (Fejér m.), Kopasz-hegy, a Csurgói-tároló partján, dolomitsziklán. Tszf.m.: kb. 200 m. Leg.: Németh, Cs. and Barina, Z., 2003.III.28. [BP 91520]. - Bakony, Veszprém megye, Hajmáskér, Malom-völgy, É-i kitettségü árnyas dolomitszikla vékony humuszrétegén. É.sz.: 47.20089; K.h.: 17.96674 ; Tszf.m.: kb. 313 m (GPS 19011). Leg.: Németh, Cs., 2007.IX.15. [BP 92939]. - Bakony: Litér (Veszprém megye): N side of hill Mogyorós-hegy, on shaded calcareous rocks. Alt.: $180 \mathrm{~m}$ a.s.l. Coll.: Lőkös, L., 04.12.1997. [BP 94483] [FAR KAs et al. 2014]. - Bakony, Veszprém megye, Márkó, Kopasz-hegy, árnyas dolomitsziklán. É.sz.: $47.15587^{\circ}$; K.h.: $17.81244^{\circ}$; Tszf.m.: kb. 423 m (GPS 2745/1). Leg.: Németh, Cs., 2008.10.19. [BP 93438]. - Bakony: Auf nördlich exponierter Dolomitfelswand bei Márkó ("Malomhegy") in $320 \mathrm{~m}$ Höhe. Date: 12.06.1948. [FeKe te et al. 1961]. - Bakony, Veszprém megye, Márkó, Malom-hegy, árnyas dolomitsziklán. É.sz.: 47.11016º K.h.: 17.81708; Tszf. m.: kb. 350 m (GPS 2753/1). Leg.: Németh, Cs., 2008.10.26. [BP 93439]. - Ba- 
kony, Veszprém megye, Márkó, Slézinger-völgy; északi kitettségben, árnyas dolomitsziklán. É.sz.: 47.16472 ; K.h.: 17.83285' Tszf.m.: kb. 413 m (GPS 2816/5). Leg.: Németh, Cs., 2009.04.13. [BP 93441]. - Bakony, Veszprém megye, Sáska, Rosta-völgy, északi kitettségben, árnyas dolomitsziklán. É.sz.: 46.96246º K.h.: 17.48175'; Tszf.m.: kb. 320 m (GPS 3245/2). Leg.: Németh, Cs., 2010.05.22. [BP 93446]. - Bakony, Veszprém megye, Sáska, a Zsivány-völgytől ÉK-re húzódó dolomit vonulatok, északi kitettségben, árnyas dolomitsziklán. É.sz.: 46.97443; K.h.: 17.48632 ${ }^{\circ}$; Tszf.m.: kb. 358 m (GPS 3424). Leg.: Németh, Cs., 2010.08.22. [BP 93447]. - Bakony, Veszprém megye; Tés; Csákány-völgy; északi kitettség-

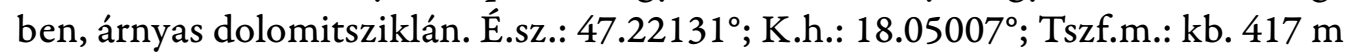
(GPS 4764, 1/1). Leg.: Németh, Cs., 2013.03.02. [BP 96264]. - Bakony, Fejér megye, Tés, Csákány-völgy, árnyas dolomitsziklán. Lat.: 47 $13^{\prime} 16.9^{\prime}$ N, Long.: $18^{\circ} 02^{\prime}$ 57.8” K, Alt.: 415 m. Leg.: Németh, Cs. (6770), 2015.06.19. [BP 96265]. Bakony, Veszprém megye, Tés, Szúnyog-völgy, É-i kitettségü, árnyas dolomitsziklán. É.sz.: 47 13' 39.3”; K.h.: 1800' 10.9”; Tszf.m.: kb. 436 m (GPS 1699/2). Leg.: Németh, Cs., 2006.XII.30. [BP 92942]. - Bakony, Veszprém megye, Várpalota, Bükkfa-kúti-árok, északi kitettségben, árnyas dolomitsziklán. É.sz.: $47^{\circ} 14^{\prime}$ 14.4"; K.h.: 18 05' 09.9"; Tszf.m.: kb. 439 m (GPS 3094/1). Leg.: Németh, Cs., 2010.04.18. [BP 93444]. - Comit. Fejér. In rupibus dolomit. silvat. vallis Burokvölgy prope Isztimér. Alt. s. met. ca: 300. Leg.: Boros, Á., 1932.05.16. [BP 36730, EGR 5641]. - Mt. Bakony: cca Várpalota, pr. Királyszállás ad versus Burok völgy, ad saxa calc. musci. Alt. cca 400 m. s. m. Leg.: Verseghy, K., 1972.09.28. [BMCRY 001255, BP 76932]. - Keleti-Bakony, Fejér megye, Isztimér, Burok-völgy, É-i kitettségü, árnyas dolomitsziklán. É.sz.: $47^{\circ} 16^{\prime} 03.4$ "; K.h.: 1808' 59.3”; Tszf.m.: kb. 278 m (GPS 1535/3). Leg.: Németh, Cs., 2006.III.26. [BP 92464]. - Keleti-Bakony, Fejér megye, Isztimér, Burok-völgy, É-i kitettségü, árnyas dolomitsziklán. É.sz.: 47 16’ 15.7”; K.h.: 1807’ 35.8” (GPS 1536/1). Leg.: Németh, Cs., 2006. IV.1. [BP 92460]. - Bakony, Fejér megye; Isztimér; Burok-völgy, elegyes karszterdőben (Fago-Ornetum). É.sz.: 47.26575 ; K.h.: 18.12028º Tszf.m.: kb. $371 \mathrm{~m}$ (GPS 2740/2; 1/1). Leg.: Németh, Cs., 2008.10.11. [BP 94067]. - Bakony, Veszprém megye, Várpalota, Kis-Burok-völgy, É-i kitettségben, árnyas dolomitszikla

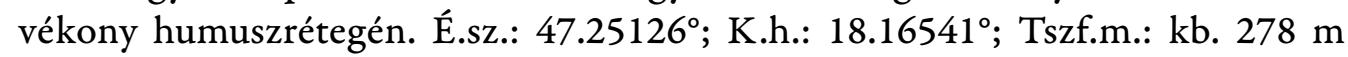
(GPS 18014/2). Leg.: Németh, Cs., 2007.VIII.1. [BP 92944]. - Bakony: Várpalota (Inota) (Veszprém m.), Síkvárgya, északi fekvésű zárt dolomitsziklagyepben. É. sz.: 47 13' 23.0"; K.h.: 18 11' 57.1"; Tszf.m.: kb. 260 m (GPS 306). Leg.: Németh, Cs., 2004.IX.26. [BP 91762]. - Comit. Veszprém. In rupestribus dolomit. silvat. vallis Várvölgy prope Várpalota. Alt. s. met. ca: 300. Leg.: Boros, Á., 1931.05.31. [EGR 5632]. - Comit. Veszprém. In rupibus dolomit. sept. silvat. vallis Vár-völgy prope Várpalota. Alt. cca. 3-350 m. s. m. Leg.: Boros, Á., 1950.05.07. [EGR 5633]. - Bakony, Veszprém megye, Várpalota, Vár-völgy, É-i kitettségü, árnyas dolomit- 
sziklán. É.sz.: 47 13'36.4"; K.h.: 18 05’ 46.1"; Tszf.m.: kb. 341 m (GPS 1681/2). Leg.: Németh, Cs., 2006.VI.24. [BP 92461]. - Bakony, Veszprém megye, Várpalota, Vár-völgy, É-i kitettségben, árnyas dolomitsziklán. É.sz.: 47.22810; K.h.: 18.10099 ; Tszf.m.: kb. 344 m (GPS 2087/3). Leg.: Németh, Cs. and Békási, I., 2007.IV.21. [BP 92945]. - Bakony, Veszprém megye, Várpalota, Vár-völgy, északi kitettségben, Fago-Ornetum árnyas dolomitszikláján. É.sz.: $47^{\circ} 13^{\prime} 39.9^{\prime \prime}$; K.h.: $18^{\circ} 06^{\prime}$ 21.0"; Tszf.m.: kb. 300 m (GPS 3088). Leg.: Németh, Cs., 2010.04.18. [BP 93443]. - Hungary, Veszprém County. Bakony Mts: Várpalota, at Vár-völgy. Lat.: 47.2279150 $\mathrm{N}$; Long.: 18.10131167 $\mathrm{E}$; Alt.: $335 \mathrm{~m}$ a.s.l. On calcareous soil among mosses. Leg.: Bauer, N., 27.05.2016 [BP 96267]. - Bakony, Veszprém megye, Veszprém, Csatári-malom és az Ördögrágta-kő között, É-i kitettségủ árnyas dolomitszikla vékony humuszrétegén. É.sz.: $47.09748^{\circ}$; K.h.: $17.86465^{\circ}$; Tszf.m.: kb. 245 m (GPS 2073). Leg.: Németh, Cs., 2007.IV.7. [BP 92947]. - Bakony, Veszprém megye, Veszprém, Csatári-malom és az Ördögrágta-kő között, É-i kitettségủ árnyas dolomitszikla vékony humuszrétegén. É.sz.: $47.09762^{\circ}$; K.h.: 17.86344우 Tszf.m.: kb. 246 m (GPS 2074). Leg.: Németh, Cs., 2007.IV.7. [BP 92948]. - Bakony, Veszprém megye, Veszprém, Csatári-malom és az Ördögrágtakő között, É-i kitettségü árnyas dolomitszikla vékony humuszrétegén. É.sz.: 47.09806 ; K.h.: 17.86148 ; Tszf.m.: kb. 232 m (GPS 2076). Leg.: Németh, Cs., 2007.IV.7. [BP 92946]. - Comit. Veszprém. In rupestribus dolomit. vallis Esztergáli-völgy prope Jutas. Alt. s. met. ca: 400. Leg.: Boros, Á., 1932.09.18. [BP 36728, EGR 5631]. - Bakony. Veszprém megye, Márkó, Esztergáli-völgy, É-i kitettségü dolomitsziklán. É.sz.: 47.16988 ; K.h.: $17.83650^{\circ}$; Tszf.m.: kb. 395 m (GPS 2052). Leg.: Németh, Cs., 2007.I.13. [BP 93437]. - In calcareis ad "Kiskuti csárda" prope Veszprém. Alt. s. m. met. ca: 280. Leg.: Boros, Á., 1920.10.09. [EGR 5630] [SzATALA 1930]. - Hungary. Veszprém County, Bakony Mts, Veszprém, Séd-völgy, near Lackó-forrás, on calcareous soil/rock. Lat.: $47^{\circ} 05^{\prime} 36.12^{\prime \prime} \mathrm{N}$; Long.: $17^{\circ} 52^{\prime} 47.08^{\prime \prime}$ E; Alt.: ca. 245 m a.s.l. Leg.: Lőkös, L. and Farkas, E., 22.06.1993 [BP 96259, BP 96260]. - Bakony, Veszprém megye, Veszprém, Laczkó-forrás, É-i kitettségü árnyas dolomitszikla vékony humuszrétegén. É.sz.: 47.09315 ${ }^{\circ}$ K.h.: $17.88171^{\circ}$; Tszf.m.: kb. 224 m (GPS 2072). Leg.: Németh, Cs., 2007.IV.07. [BP 92949]. Comit. Veszprém, ad terram muscosa, ad margines carpinetis, prope "Laczkóforrás" in loci "Veszprémvölgy" in opp. Veszprém. Alt. cca. 235 m. s. m. 47 05' 50.61”, 17 53’ 00.10", Veszprém, 17.01.2015. Leg.: M. Sinigla. [BMCRY 001442]. - Bakony, Veszprém megye, Mohos-kő, É-i kitettségü mészkősziklán. É.sz.: 47.18640 ; K.h.: 17.88183우 Tszf.m.: kb. 390 m (GPS 2048). Leg.: Németh, Cs., 2007.I.13. [BP 92950]. - Bakony, Veszprém megye, Veszprém, Mohos-kő, északias kitettségben, árnyas mészkősziklán. É.sz.: $47.18642^{\circ}$, K.h.: $17.88146^{\circ}$, Alt.: 396 m. Leg.: Erzberger, P. and Németh, Cs. (6709), 2015.05.31. [BP 96266]. - Bakony, Veszprém megye, Veszprém, Sas-hegy nyugati letörése, É-i kitettségü ár- 


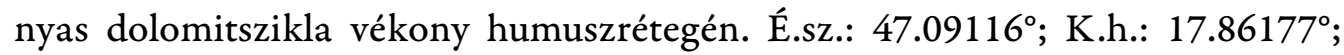
Tszf.m.: kb. 286 m (GPS 2077). Leg.: Németh, Cs., 2007.IV.7. [BP 92952]. Bakony, Veszprém megye, Veszprém, Tekeres-völgy, É-i kitettségű árnyas dolomitszikla vékony humuszrétegén. É.sz.: $47.08855^{\circ}$; K.h.: $17.86108^{\circ}$; Tszf.m.: kb. 266 m (GPS 2079). Leg.: Németh, Cs., 2007.IV.7. [BP 92953]. - Bakony, Veszprém megye, Veszprém, Tekeres-völgy, É-i kitettségü árnyas dolomitszikla vékony humuszrétegén. É.sz.: $47.08855^{\circ}$; K.h.: 17.86040 ; Tszf.m.: kb. 286 m (GPS 2081). Leg.: Németh, Cs., 2007.IV.7. [BP 92954]. - Bakony, Veszprém megye, Veszprém, Tekeres-völgy, északi kitettségü, árnyas dolomitszikla vékony humuszrétegén.

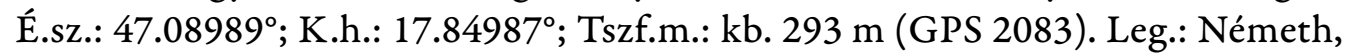
Cs., 2007.IV.7. [BP 92955]. - Bakony, Veszprém megye, Veszprém, Tekeres-völgy (a Köris-hegy nyugati letörése), északi kitettségü, árnyas dolomitszikla vékony humuszrétegén. É.sz.: $47.08200^{\circ}$; K.h.: $17.84704^{\circ}$; Tszf.m.: kb. 289 m (GPS 2084). Leg.: Németh, Cs., 2007.IV.7. [BP 92956].

Balaton-felvidék - Hungary, Veszprém County. Balaton-felvidék, Balatonfüred, Koloska-völgy, Koloska-sziklák above Koloska-forrás, on shaded calcareous rocks. Lat.: 46 59' 27.47” N; Long.: $17^{\circ} 53^{\prime}$ 3.42” E; Alt.: 265 m. Leg.: Lőkös, L., Farkas, E., Lőkös, D. and Lőkös, L. M., 24.04.2011 [BP 96263]. - Balatonfüred, supra Koloska-forrás, in saxa dolomit., 561468, 183682, $271 \mathrm{~m}$. Leg.: M. Sinigla, 2015.07.03. [BMCRY 002198]. - Balaton-felvidék, Veszprém megye, Felsőörs, Király-kúti-völgy, árnyas dolomitsziklán. É.sz.: 47.01244º K.h.: 17.93541 ${ }^{\circ}$; Tszf.m.: kb. 248 m. (GPS 3742/5, 1/1). Leg.: Németh, Cs., 2011.07.24. [BP 93938]. - Comit. Veszprém, ad terram muscosa, in cacumine Quercetum, supre vallem “Király-kúti-völgy", prope pag. Lovas. $47^{\circ} 00^{\prime} 44.99^{\prime}, 17^{\circ} 56^{\prime} 07.32$ ”, alt. cca. 282 m. s. m. Leg.: M. Sinigla, 10.06.2015. [BMCRY 001978]. - Felsőörs, Kopasz-tető (Malom-völgy), in fruticetis Quercetum, 565403, 186658, $257 \mathrm{~m}$. Leg.: M. Sinigla, 2015.07.06. [BMCRY 002199]. - Comit. Veszprém, ad saxa dolomit. (É-ÉNY), in cacumine fruticetis, in loci “Zádor-vár”, prope pag. Pécsely. $46^{\circ} 58^{\prime} 23.50^{\prime \prime}, 17^{\circ} 46^{\prime} 17.55^{\prime \prime}$, alt. cca. 337 m. s. m. Leg.: M. Sinigla, 03.06.2015. [BMCRY 001901]. - Balaton-felvidék, Veszprém megye, Vászoly, Bab-völgy (Nagyvár-tető), északi kitettségben, árnyas dolomitsziklán. Lat.: $46^{\circ} 56^{\prime} 01.2^{\prime \prime} \mathrm{N}$, Long.: $17^{\circ} 46^{\prime} 19.8^{\prime \prime}$ K, Alt.: 284 m. Leg.: Németh, Cs., Erzberger, P., Kovács, A. and Nagy, Z. (7053), 2015.07.04. [BP 96270].

Buda Mts - Comit. Pest. Ad terram in monte "Hunyady hegy" prope Budapest; alt. ca. 300 m. s. m. Leg.: Szatala, Ö. (2412), 1918.04.28. [BP 36703] [SzATALA 1925, 1930]. - Budapest. In dolomiticis sept.-occ. montis Hunyadi-orom. Alt. cca 250-300 m. s. m. Leg.: Boros, Á., 1946.03.15. [EGR 5656]. - Budaihegység, Budapest, Hunyad-orom, É-i kitettségü, árnyas szikla humuszrétegén. É.sz.: 47.51550 ; K.h.: 18.97449 ; Tszf.m.: kb. 280 m (GPS 2053). Leg.: Németh, Cs., 2007.III.15. [BP 92933]. - Comit. Pest. Ad terram in monte "Ördögorma" 
prope Budapest; alt. ca. 300 m. Leg.: Szatala, Ö. (0998), 1916.07.11. [BP 36699] [Szatala 1925, 1930]. - Comit. Pest. In monte "Ördögorma" prope Budapest; alt. ca. 300 m. Leg.: Szatala, Ö., 1916.07.11. [BP 2853] [Szatala 1925, 1930]. - Buda Mts, Nagykovácsi, ca 800 m NE of Felső-Zsíros-hegy, close to the Antal (Antónia)-árok. On shaded calcareous soil. Alt. ca. $340 \mathrm{~m}$. Leg.: Lőkös, L., 2002.09.13. [BP 91267]. - Comit. Pest. In locis dolomit. silvat. "Urasági-erdo"” prope pag. Nagykovácsi. Alt. cca 4-450 m. s. m. Leg.: Boros, Á., 1948.03.21. [EGR 5654]. - Comit. Pest. In dolomiticis montis Alsó-Zsíros-hegy prope Pilisszentiván. Alt. cca: 3-400 m. s. m. Leg.: Boros, Á., 1946.05.26. [BP 36725, EGR 5653]. - Hungary, Pest County. Buda Mts, Csabai-árok near Pilisszentiván. On calcareous soil. Lat.: $47^{\circ} 36^{\prime} 19.0^{\prime \prime} \mathrm{N}$; Long.: $18^{\circ} 52^{\prime} 04.1^{\prime \prime} \mathrm{E}$; Alt.: ca $330 \mathrm{~m}$ a.s.l. Leg.: Bauer, N. and Somlyay, L., 16.04.2008. [BP 96276]. - Comit. Pest. In dolomiticis "Horh" montis Kisszénás prope Pilisszentiván. Alt. cca 392 m. s. m. Leg.: Boros, Á., 1945.05.20. [EGR 5652]. - Comit. Pest. In dolomiticis "Horch" montis Kisszénás prope Pilisszentiván. Alt. cca. 392 m. s. m. Leg.: Boros, Á., 1945.11.01. [BP 36692]. - Hungary, Pest County. Buda Mts, Pilisszentiván, Kis-Szénás, on gritty road-bank between Hosszú-árok and Iváni-hegy along dirty road. On shaded calcareous soil. Lat.: $47.599318^{\circ} \mathrm{N}$; Long.: $18.874150^{\circ} \mathrm{E}$; Alt.: $370 \mathrm{~m}$ a.s.l. Leg.: Lőkös, L., 25.05.1988 [BP 96272]. - Ad terram glareosam dolomiticam in monte "Nagyszénáshegy" pr. Pilisszentiván alt. cca 300 m. [Tim Kó 1925, Szatala 1930]. - Comit. Pest. In rupibus dolomit. sept. montis Szarvas-hegy prope Pesthidegkút. Alt. cca 300 m. s. m. Leg.: Boros, Á., 1944.10.15. [EGR 5655] [Boros 1944]. - Hungary, Pest County. Buda Mts, northern side of Mt Szarvashegy (Solymár). Western side of a small ridge W of Kötők padja along tourist path blue square, in rocky grassland with Sesleria sadleriana. On shaded calcareous soil. Lat.: $47.576515^{\circ} \mathrm{N}$; Long.: $18.967620^{\circ} \mathrm{E}$; Alt.: $335 \mathrm{~m}$ a.s.l. Leg.: Lőkös, L., 19.03.1989 [BP 96273]. - Hungary, Pest County. Buda Mts, northern side of Mt Szarvas-hegy (Solymár) near Kötők padja along tourist path blue line, in rocky grassland with Sesleria sadleriana. On shaded calcareous soil. Lat.: $47.576307^{\circ} \mathrm{N}$; Long.: 18.968507 ${ }^{\circ}$; Alt.: 340 m a.s.l. Leg.: Lőkös, L., 19.03.1989 [BP 96274]. Hungary, Pest County. Buda Mts, Solymár, Mt Szarvas-hegy, northern slope, near Kötők padja, along the tourist path. On shaded calcareous soil. Lat.: $47.576307^{\circ}$ N; Long.: 18.968507 E; Alt.: 340 m a.s.l. Leg.: Lőkös, L., 26.04.2003 [BP 96275].

Bükk Mts - Comit. Borsod. In rupestribus calcareis montis Bélkő prope Bélapátfalva. Alt. s. met. ca: 5-780. Leg.: Boros, Á., 1934.07.09. [BP 36719, EGR 5649]. - Com. Heves. Bükk: Felsőtárkány, in decl. m. Csákpilis. Substr.: terra muscosa. Alt.: 400 m. s. m. Leg.: Fóriss, F. (7965), 1930.07.15. [BP 67517, EGR 3535, JPU]. - Bükk hegység, Buzgókő. Leg.: Kiszelyné Vámosi, A. (No. 1.), 1987.07.16. [EGR 4079] [Kiszely-VÁmosi et al. 1989]. - Bükk hegység, Buzgókő. Szikla északi oldalán. Leg.: Kiszelyné Vámosi, A. (No. 1.), 1987.07.16. [EGR 4080] [KISZELY- 
VÁmosi et al. 1989]. - Comit. Borsod. In rupibus calc. silvat. vallis Ablakoskő prope Nagyvisnyó. Alt. s. met. ca: 7-800. Leg.: Boros, Á., 1934.07.03. [EGR 5647]. - Comit. Borsod. In rupibus calcareis silvat. supra vallem Ablakoskő-völgy montis Bálvány prope Nagyvisnyó. Alt. cca.: 850 m. s. m. Leg.: Boros, Á., 1952.09.29. [BP 50551]. - Comit. Borsod. In rupibus calc. sept. silvat. montis Hollókő prope Nagyvisnyó. Alt. cca: 6-800 m. s. m. Leg.: Boros, Á., 1950.10.03. [BP 36722, EGR 5646]. - Hungary. Borsod-Abaúj-Zemplén County. Bükk National Park, Bükk Mts, Ómassa, Mt Jávor-hegy, northern slope facing to Ómassa, alt. ca $600 \mathrm{~m}$ a.s.l. On calcareous soil. Leg.: Lőkös, L. (10/85Y), 26.09.1985 [BP 96278]. - Hungary. Borsod-Abaúj-Zemplén County. Bükk National Park, Bükk Mts, Ómassa, Mt. Jávor-hegy, alt. ca $500 \mathrm{~m}$ a.s.l. On calcareous soil. Leg.: Lőkös, L. (12/86N), 24.04.1986 [BP 96279]. - Comit. Borsod. In rupibus calc. silvat. "Vöröskő" prope Ómassa. Alt. s. met. ca: 5-600. Leg.: Boros, Á., 1932.07.03. [BP 36727, EGR 5648]. - Comit. Borsod. In rupestribus calcareis fissuris ad Uppony. Alt. s. met. ca: 250-400. Leg.: Boros, Á., 1934.07.07. [BP 36704, EGR 5650]. - Borsod-AbaújZemplén County. N-Hungary. Pass “Upponyi-szoros”, Simakő. É.sz.: 48 12,870, K.h.: $20^{\circ}$ 26,856, Alt.: 203 m. On limestone rock. Leg.: Molnár, K. (U0505/Q), 2005.08.03. [EGR 4518] [MOLNÁR and LöKÖs 2007]. - Hungary. Borsod-AbaújZemplén County. Uppony Mts, Uppony, “Upponyi-szoros” gorge, northern side of Mt Simakő. Lat.: $48^{\circ} 12^{\prime}$ 51.18” N, Long.: $20^{\circ} 26^{\prime} 52.92^{\prime \prime}$ E, Alt.: 225 m a.s.l. On limestone rock. Leg.: Lőkös, L. and Molnár, K., 03.08.2005 [BP 96280].

Gerecse Mts - [Neszmély], Sipsó-völgy, alt. ca. 260 m.; [Nyergesújfalu], Cser-völgy, alt. ca. 250 m.; [Süttő], Haraszt-hegy, alt. ca. 260 m.; [Süttő], Tumulusok, alt. ca. 200 m. [Solymosi 1979]. - Flora Hungar. Prope pag. Szár, mont. Zuppa-hegy. In decliv. meridion. dolomitica. Alt. ca. $250 \mathrm{~m}$. Leg.: Pénzes, A., 1948.04.18. [BP 85054]. - Gerecse: Szárliget (Fejér m.), Cseresznyés-árok, északi fekvésű dolomitszikla vékony humuszrétegén. É.sz.: 47³0'38.6”; K.h.: $18^{\circ} 30^{\prime}$ 28.4"; Tszf.m.: kb. 280 m (GPS 362). Leg.: Németh, Cs., 2004.II.21. [BP 91763].

Keszthely Mts - Keszthelyi-hegység: Balatongyörök (Zala m.), Bondorhálás, É-i kitettségben, lombosmoha-gyepben; É.sz.: 46 $47^{\prime} 18.74$ "; K.h.: $17^{\circ} 20^{\prime}$ 12.48"; Tszf.m.: 272 m (GPS 2533). Obs.: Németh, Cs. and Rezneki, R., 2008.06.22. - Keszthelyi-hegység, Zala megye, Balatongyörök, Hajagos (Kígyós-völgy), árnyas dolomitsziklán. É.sz.: $46.79179^{\circ}$, K.h.: 17.33408º Tszf.m.: kb. 258 m (GPS 3825/4; 1/1). Leg.: Németh, Cs., 2011.08.06. [BP 93940]. - Keszthelyi-hegység, Zala megye, Balatongyörök, Szamár-kő, árnyas dolomitsziklán. É.sz.: $46.78730^{\circ}$; K.h.: 17.33797; Tszf.m.: kb. 269 m (GPS 2530). Leg.: Németh, Cs. and Rezneki, R., 2008.06.22. [BP 92934]. - Comit. Veszprém, prope opp. Keszthely, in montium "Keszthelyi-hegység", in Pineto ad terram. Leg.: Gallé, L., 1956.07.08. [BP 95980] [GALLÉ 1961, 1973]. - Keszthelyi-hegység: Gyenesdiás, shaded calcareous rocks at Kömell. Alt. ca. 280 m a.s.l. Leg.: Papp, B., 2002.III.31. [BP 91764]. 
- Keszthelyi-hegység, Zala megye, Gyenesdiás, Öreg-Szék-tető, árnyas dolomitsziklán. É.sz.: 46.80753 ${ }^{\circ}$ K.h.: $17.31440^{\circ}$; Tszf.m.: kb. 343 m (GPS 3861/4; 1/1). Leg.: Németh, Cs., 2011.08.13. [BP 93941]. - Comit. Veszprém, pr. opp. Keszthely, supra pagum "Gyenesdiás", in decl. montis "Petőhegy", ad terram in Pinetis. Alt. ca. 300 m s. m. Leg.: Gallé, L., 1956.07.08. [SZE, as Solorina saccata var. spongiosa] [GALlÉ 1961, 1973]. - Comit. Veszprém, prope opp. Keszthely, in decl. montis "Petőhegy", ad terram, in Pineto. Leg.: Gallé, L., 1956.07.08. [BP 95981, as Solorina saccata var. spongiosa] [GALLÉ 1961, 1973]. - Keszthelyi-hegység, Veszprém megye, Lesencefalu, Somos-tető, árnyas dolomitsziklán. É.sz.: $46.84419^{\circ} \mathrm{N}$, K.h.: 17.32756 ${ }^{\circ}$ E; Tszf.m.: kb. 350 m (GPS 3891/3; 1/1). Leg.: Németh, Cs., 2011.08.21. [BP 93942]. - Hungary, Keszthely Mts, Mt Púpos-hegy at Rezi, western extension. Lat.: $46.866335^{\circ} \mathrm{N}$; Long.: $17.222578^{\circ} \mathrm{E}$; Alt.: $280 \mathrm{~m}$ a.s.l. On calcareous soil among dolomitic rocks. Leg.: Farkas, E., Guttová, A. and Lőkös, L., 11.05.2010. [BP 96281]. - Keszthelyi-hegység, Zala megye, Vállus, a Vadlány-lik-barlang felett, északi kitettségben, árnyas dolomitsziklán. É.sz.: $46.84451^{\circ}$; K.h.: $17.30545^{\circ}$; Tszf.m.: kb. 260 m (GPS 3324/2). Leg.: Németh, Cs. and Schuler, E., 2010.07.17. [BP 93448]. - Keszthelyi-hegység, Zala megye, Vonyarcvashegy, Csalános-völgy, árnyas dolomitsziklán. É.sz.: $46.77937^{\circ} \mathrm{N}$, K.h.: $17.32444^{\circ} \mathrm{E}$; Tszf.m.: kb. $245 \mathrm{~m}$ (GPS 3813/7; 1/1). Leg.: Németh, Cs., 2011.08.06. [BP 93939].

Köszeg Mts - Comit. Vas: Bozsok, in saxo quodam sub mte Kalaposkő, in caespite ctenidii mollusci. Leg.: Gáyer, Gy., 1931.10. [SAMU B.25] [Lö Kös et al. 1997]. - Velem-Péterics-hegy, sziklai erdeifenyvesben. [Vida 1956: tab., 1955] [LöKös et al. 1997].

Pilis Mts - Comit. Pest: ad terram in monte "Vaskapu"; ca. 300 m. Leg.: Szatala, Ö. (3932), 1921.07.22. [BP 36702] [Szatala 1925, 1930]. - Comit. Pest. In rupibus calcar. silvat. "Vaskapu szikla" montis Pilis prope Pilisszántó. Alt. cca 600 m. s. m. Leg.: Boros, Á., 1946.04.04. [EGR 5651]. - Mt. "Vaskapu-hegy" at rocks of "Vaskapu", NW of Pilisszentkereszt. Alt. $550 \mathrm{~m}$ s. m. Leg.: Farkas, E. (8335/H), 1983.08.03. [VBI] [Far Kas 1990]. - Hungary, Pest County. Pilis Mts, Mt Vaskapu ca. $2 \mathrm{~km} \mathrm{NW}$ of Pilisszentkereszt, on calcareous rock among Sesleria grasses. Lat.: $47.700621^{\circ} \mathrm{N}$; Long.: $18.876309^{\circ} \mathrm{E}$; Alt.: $535 \mathrm{~m}$ a.s.l. Leg.: Lőkös, L., 05.05.1990 [BP 96271]. - "Pilis-hegység" at the NE side of the Mt. "Fekete-hegy". On the rocks near the road S of Pilisszentlélek. Alt. $400 \mathrm{~m} \mathrm{s.} \mathrm{m.} \mathrm{Leg.:} \mathrm{Farkas,} \mathrm{E.}$ and Lőkös, L. (8527/G), 1985.05.05. [VBI] [FARKAs 1990].

Vértes Mts - Vértes, Fejér megye, Csákberény, Cseresnyés-völgy, É-i kitettségü dolomitsziklán. É.sz.: 47.38246º K.h.: 18.32536º Tszf.m.: kb. 408 m (GPS 1939/4). Leg.: Németh, Cs., 2006.X.14. [BP 92930]. - Vértes, Fejér megye, Csákberény, Csete-völgy, É-i kitettségű dolomitszikla-repedésben, humuszon. É.sz.: $47^{\circ} 21^{\prime}$ 55.7”; K.h.: 18 17' 58.6”; Tszf.m.: kb. 407 m (GPS 1511). Leg.: Németh, Cs., 2006.III.11. [BP 92462]. - Vértes, Fejér megye, Csákberény, Csonka-bükk, É-i 


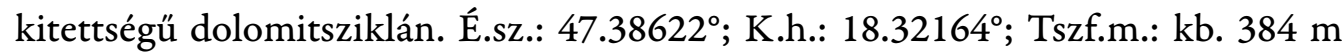
(GPS 1952/1). Leg.: Németh, Cs., 2006.X.21. [BP 92932]. - Vértes, Fejér megye, Csákberény, Csonka-bükk, É-i kitettségü dolomitsziklán. É.sz.: 47.386080 ; K.h.: 18.322870 ; Tszf.m.: kb. 399 m (GPS 1954). Leg.: Németh, Cs., 2006.X.21. [BP 92931]. - Vértes, Fejér megye, Csákberény, Csonka-bükk; északi kitettségben, árnyas dolomitszikla-kibúváson. É.sz.: $47.38630^{\circ}$; K.h.: $18.32166^{\circ}$; Tszf.m.: kb. 403 m (GPS 2823/2). Leg.: Németh, Cs., 2009.04.19. [BP 93442]. - Vértes, Fejér megye, Csákberény, Gémförtés-völgy, északi fekvésű dolomitszikla vékony humuszrétegén. É.sz.: $47^{\circ} 21^{\prime}$ 12.2”; K.h.: 18 18' 13.1"; Tszf.m.: kb. 360 m. Leg.: Németh, Cs., 2003.IV.19. [BP 91438]. - Vértes: Csákberény (Fejér m.), Gémförtésvölgy, É-i kitettségü dolomitszikla humuszán. É.sz.: 47² 21' 14.4”; K.h.: $18^{\circ} 18^{\prime}$ 08.4"; Tszf.m.: kb. 360 m (GPS 638/1). Leg.: Németh, Cs., 2005.04.16. [hb. Németh]. - Comit. Fejér. In rupestribus dolomiticis silvaticis supra vallem Horogvölgy pr. Csákberény. Alt. s. met. ca: 3-350. Leg.: Boros, Á., 1936.06.09. [EGR 5640]. - Vértes, Fejér megye, Csákberény, Kopasz-hegy nyugati letörése, árnyas dolomitsziklán. É.sz.: 47.35014 ; K.h.: 18.29984º Tszf.m.: kb. 214 m (GPS 4214; 1/1). Leg.: Németh, Cs., 2012.03.17. [BP 94057]. - Vértes, Fejér megye, Csákberény, Kőkapu-völgy, É-i kitettségü dolomitszikla humuszán. É.sz.: 47 21'44.5”; K.h.: 18 18' 25.0"; Tszf.m.: kb. 388 m (GPS 655/1). Leg.: Németh, Cs., 2005.IV.16. [BP 92231]. - Comit. Fejér. In rupibus dolom. dumet. "Meszes-völgy" prope Csákberény. Alt. s. met. ca: 3-380. Leg.: Boros, Á., 1934.04.29. [EGR 5639]. Vértes, Fejér megye, Csákberény, Meszes-völgyi-lyuk mellett, északi fekvésü dolomitsziklafal kis ürege. É.sz.: $47^{\circ} 21^{\prime}$ 48.6"; K.h.: 18 18' 31.2"; Tszf.m.: kb. 340 m. Leg.: Németh, Cs., 2002.III.17. [BP 91436]. - Vértes: Csákberény (Fejér m.), Meszes-völgyi-lyuk felett, É-i kitettségü mohás dolomitsziklán. Alt. ca. $332 \mathrm{~m} \mathrm{s.} \mathrm{m.}$ $47^{\circ} 21^{\prime} 48.6^{\prime \prime} \mathrm{N} ; 1^{\circ} 18^{\prime} 31.2^{\prime \prime} \mathrm{E}$ (GPS 511). Obs.: Németh, Cs., 2005.04.16. - Vértes, Fejér megye, Csákberény, Meszes-völgyi-lyuk mellett, ÉK-i kitettségü mohás dolomitsziklán. É.sz.: 47² 21' 49.7”; K.h.: 18 18' 32.8”; Tszf.m.: kb. 328 m (GPS 514). Leg.: Németh, Cs., 2005.IV.16. [BP 92221]. - Vértes, Fejér megye, Csákvár, Pamlag-völgy, árnyas dolomitsziklán. É.sz.: $47.43035^{\circ}$; K.h.: $18.44183^{\circ}$; Tszf.m.: kb. 372 m (GPS 4851, 1/1). Leg.: Németh, Cs., 2013.05.04. [BP 96268]. - Comit. Fejér. In rupestribus dolomit. dumetosis Pap-irtás prope Csákberény. Alt. ca. 3-400 m. s. m. Leg.: Boros, Á., 1936.04.26. [BP 36706, EGR 5638]. - Vértes, Fejér megye, Csákberény, Pap-irtás É-i letörése, É-i kitettségű dolomitszikla humuszán. É.sz.: 47²1' 06.3”; K.h.: 18 18' 21.2"; Tszf.m.: kb. 336 m (GPS 644). Leg.: Németh, Cs., 2005.IV.16. [BP 92232]. - Vértes, Fejér megye, Csákberény, Somos-völgy, É-i kitettségű dolomitsziklán lombosmoha gyepben. É.sz.: 47² 21'37.8”; K.h.: $18^{\circ} 18^{\prime}$ 42.0"; Tszf.m.: kb. 351 m (GPS 660). Leg.: Barina, Z. and Németh, Cs., 2005.IV.22. [BP 92222]. - Vértes, Fejér megye, Csákberény, Somos-völgy, É-i kitettségű dolomitsziklán lombos moha gyepben. É.sz.: 47² 21' 37.6”; K.h.: 18 18' 39.6”; Tszf.m.: 
kb. 343 m (GPS 661). Leg.: Barina, Z. and Németh, Cs., 2005.IV.22. [BP 92223]. - Vértes, Fejér megye, Csákberény, Szedres (Juhdöglő)-völgy, É-i kitettségü dolomitsziklán. É.sz.: $47^{\circ} 22^{\prime} 48.5^{\prime \prime}$; K.h.: 18 $19^{\circ}$ 42.2” (GPS 1015). Leg.: Barina, Z. and Németh, Cs., 2005.VII.27. [BP 92224]. - Vértes, Fejér megye, Csákberény, Ugróvölgyi-lyuk mellett, északi fekvésü dolomitszikla vékony humuszrétegén. É.sz.: $47^{\circ} 22^{\prime}$ 09.9”; K.h.: 18 18' 59.7”; Tszf.m.: kb. 330 m (GPS 346). Leg.: Németh, Cs., 2003.IV.19. [BP 91439]. - Vértes, Fejér megye, Csákberény, Ugró-völgy, É-i kitettségű dolomitszikla-repedésben. É.sz.: $47^{\circ} 22^{\prime} 12.8^{\prime \prime}$; K.h.: $18^{\circ} 18^{\prime} 52.3$ "; Tszf.m.: kb. 406 m (GPS 777/1). Leg.: Németh, Cs., 2005.V.16. [BP 92233]. Vértes, Fejér megye, Csákberény, Ugró-völgy, É-i kitettségü dolomitsziklarepedésben. É.sz.: $47^{\circ} 22^{\prime}$ 04.9”; K.h.: 18 19' 12.1"; Tszf.m.: kb. 355 m (GPS 780/1). Leg.: Németh, Cs., 2005.V.16. [BP 92230]. - Vértes: Csákberény (Fejér m.), Ugró-völgy, É-ÉK-i kitettségü dolomitszikla repedésben. É.sz.: $47^{\circ} 22^{\prime} 03.1^{\prime \prime}$; K.h.: $18^{\circ} 19^{\prime} 17.5^{\prime \prime}$; Tszf.m.: kb. 372 m (GPS 805). Obs.: Németh, Cs., 2005.05.16. - Comit. Fehér. In declivibus calc. supra Csákvár. Alt. s. met. ca: 2-300 m. Leg.: Boros, Á., 1928.04.01. [BP 36721, EGR 5635]. - Comit. Fejér. In rupibus dolomit. "Balog-völgy" supra pag. Csákvár. Alt. cca: 250 m. s. m. Leg.: Boros, Á., 1947.04.06. [BP 36726]. - Vértes, Fejér megye, Csákberény, Hosszú-hegy-Kálvária-völgy, ÉÉK-i kitettségü dolomitszikla humuszán. É.sz.: 47² 24' 14.6”; K.h.: $18^{\circ} 26^{\prime} 16.4$ "; Tszf.m.: kb. 285 m (GPS 619). Leg.: Németh, Cs., 2005.IV.3. [BP 92228]. - Vértes: Csákvár (Fejér m.), Hosszú-hegy-Kálvária-völgy, É-ÉK-i kitettségű dolomitszikla humuszán. É.sz.: 47²4' 15.1"; K.h.: $18^{\circ} 26^{\prime}$ 14.5”; Tszf.m.: kb. 286 m (GPS 621). Obs.: Németh, Cs., 2005.IV.03. - Vértes, Fejér megye, Csákvár, Hosszú-hegyKálvária-völgy, É-ÉK-i kitettségü dolomitszikla humuszán. É.sz.: $47^{\circ} 24$ ' 15.7”; K.h.: $18^{\circ} 26^{\prime}$ 09.9"; Tszf.m.: kb. 287 m (GPS 623). Leg.: Németh, Cs., 2005.IV.3. [BP 92229]. - Vértes: Csákvár (Fejér m.), Hosszú-hegy-Kálvária-völgy, É-ÉK-i kitettségű dolomitszikla humuszán. É.sz.: 47²4' 15.7”; K.h.: 18²6’07.8”; Tszf.m.: kb. 310 m (GPS 624). Obs.: Németh, Cs., 2005.IV.03. - Vértes: Csákvár (Fejér m.), Hosszú-hegy-Kálvária-völgy, É-ÉK-i kitettségű dolomitszikla humuszán. É.sz.: $47^{\circ} 24^{\prime} 15.9^{\prime \prime}$; K.h.: $18^{\circ} 26^{\prime} 07.2^{\prime \prime}$; Tszf.m.: kb. 311 m (GPS 625). Obs.: Németh, Cs., 2005.IV.03. - Comit. Fejér. In rupestribus dolomit. silvat. vallis Kőlik-völgy pr. Csákvár. Alt. s. met. ca: 2-300. Leg.: Boros, Á., 1937.04.04. [BP 36723, EGR 5636]. - Vértes, Fejér megye, Csákvár, Kőlik-völgy, É-ÉK-i kitettségü dolomitszikla humuszán. É.sz.: 47² 23’ 44.4"; K.h.: 18²6' 30.9”; Tszf.m.: kb. 319 m (GPS 608). Leg.: Németh, Cs., 2005.IV.3. [BP 92227]. - Comit. Fejér. In rupibus dolom. silvat. supra vallem "Nagyvaskapu" prope Csákvár. Alt. s. met. ca: 200. Leg.: Boros, Á., 1934.04.15. [BP 36709, EGR 5634]. - Comit. Fejér. In rupibus dolomiticis sept. silvat. ad versus montem Ökörállás prope Csákvár. Alt. cca $250 \mathrm{~m}$. s. m. Leg.: Boros, Á., 1962.05.18. [EGR 5637]. - Vértes, Fejér megye, Csákvár, Öreg-hegy (a Szóló-kő mellett) északi letörése, északi kitettségben, dolomitszikla-kibúváson. 


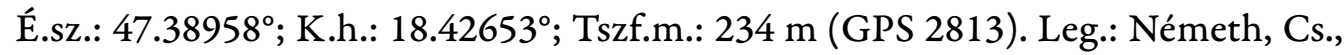
2009.04.11. [BP 93440]. - Vértes, Fejér megye, Csákvár, Róka-hegy, É-ÉK-i kitettségü dolomitszikla humuszán. É.sz.: 47 23' 58.9”; K.h.: 18²4' 56.9”; Tszf.m.: kb. 349 m (GPS 628). Leg.: Németh, Cs., 2005.IV.3. [BP 92225]. - Vértes, Fejér megye, Csákvár, Szóló-kő, északi kitettségben, árnyas dolomitsziklán. É.sz.: 47.38663; K.h.: 18.43376 ${ }^{\circ}$; Tszf.m.: kb. 222 m (GPS 3200/2; 1/1). Leg.: Németh, Cs., 2010.05.09. [BP 93445]. - Vértes, Fejér megye, Csákvár, Zöld-hegy, É-i kitettségü dolomitsziklán. É.sz.: 47² 24’ 29.1"; K.h.: 18²6’ 12.1"; Tszf.m.: kb. 295 m (GPS 1362). Leg.: Németh, Cs., 2005.X.15. [BP 92226]. - Vértes, Fejér megye, Gánt, bányatelep, É-i kitettségben, dolomitsziklán. É.sz.: 47²2'09.7”; K.h.: $18^{\circ}$ 23' 26.4"; Tszf.m.: kb. 195 m (GPS 1362). Leg.: Barina, Z., 2005.IX.24] [BP 92463]. - Vértes, Fejér megye, Gánt, a Petőfi Sándor úttól K-re, a kőbányák felé, É-i kitettségű dolomitsziklán. É.sz.: $47^{\circ} 23^{\prime} 12.8^{\prime \prime}$; K.h.: 18²3' 16.3” (GPS 1221). Leg.: Barina, Z. and Németh, Cs., 2005.IX.4. [BP 92235]. - Vértes, Fejér megye, Gánt (Kápolnapuszta), Hosszú-völgy, árnyas dolomitsziklán. É.sz.: 47²3’ 48.1"; K.h.: $18^{\circ} 21^{\prime}$ 31.0"; Tszf.m.: kb. 276 m (GPS 6422, KEF 8676.1). Leg.: Németh, Cs., Békefi, N. and Mészáros, G., 2014.12.21. [BP 96269]. - Vértes, Fejér megye, GántKápolnapuszta, Juh-völgy, É-ÉK-i kitettségü dolomit-sziklaüregben. É.sz.: $47^{\circ} 23^{\prime}$ 37.3"; K.h.: $18^{\circ} 21^{\prime}$ 16.4"; Tszf.m.: kb. 313 m (GPS 835/1). Leg.: Németh, Cs., 2005.V.21. [BP 92234]. - Vértes: Gánt-Kápolnapuszta (Fejér m.), Juh-völgy, É-i

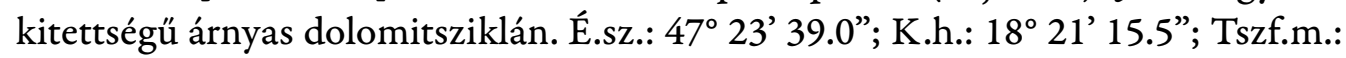
kb. 297 m (GPS 838). Obs.: Németh, Cs., 2005.05.21. - Vértes, Fejér megye, Vértesboglár, Macska-völgy(gödör), É-i kitettségü dolomitsziklán, mohagyepben. É.sz.: 47 27' 30.5”; K.h.: $18^{\circ} 27^{\prime}$ 19.3”; Tszf.m.: kb. 313 m (GPS 1428). Leg.: Németh, Cs., 2005.X.29. [BP 92220]. - Vértes, Fejér megye, Vérteskozma, Boglárioldal, É-i kitettségű dolomitszikla-repedésben. É.sz.: 47 $27^{\prime} 12.5^{\prime \prime}$; K.h.: $18^{\circ} 26^{\prime}$ 52.0"; Tszf.m.: kb. 336 m (GPS 726/1). Leg.: Németh, Cs., 2005.V.13. [BP 92215]. - Comit. Fehér. Vértes. In valle "Fáni völgy" prope Vértes Kozma. Leg.: Degen, Á., 1932.05.08. [BP 36696]. - Comit. Fejér. In rupestribus dolomit. septem. sub monte Nagysomló vallis Fáni-völgy prope pagum Vérteskozma. Alt. cca $350 \mathrm{~m}$. s. m. Leg.: Boros, Á., 1940.05.27. [EGR 5645]. - Vértes, Fejér megye, Vérteskozma, Fáni-völgy, É-i kitettségü dolomitszikla-repedésben. É.sz.: $47^{\circ} 27^{\prime} 33.4^{\prime \prime}$; K.h.: $18^{\circ}$ 27' 25.7"; Tszf.m.: kb. 281 m (GPS 732/1). Leg.: Németh, Cs., 2005.V.13. [BP 92214]. - Vértes, Fejér megye, Vérteskozma, Fáni-völgy, É-i kitettségű dolomitszikla-repedésben. É.sz.: 47 27’30.8”; K.h.: 18²7’ 19.8”; Tszf.m.: kb. 320 m (GPS 736/1). Leg.: Németh, Cs., 2005.V.13. [BP 92213]. - Comit. Fejér. In rupibus dolomit. silvat. ad "Macska-gödör" vallis "Fánien-völgy" prope Vérteskozma. Alt. s. met. ca: 300. Leg.: Boros, Á., 1932.05.01. [BP 36729, EGR 5644] [Boros 1933]. - Vértes: Vérteskozma (Fejér m.), Fáni-völgy, Macska-gödör, Fago-Ornetum és Festuco pallenti-Brometum pannonici határán, É-i kitettségü dolomitsziklán. É.sz.: 
$47^{\circ} 27^{\prime}$ 33.0”; K.h.: 18 27’ 22.4”; Tszf.m.: kb. 295 m (GPS 558/1). Leg.: Németh, Cs., 2005.03.25. [hb. Németh]. - Vértes, Fejér megye, Vérteskozma, Fáni-völgy, Macska-gödör, Fago-Ornetum és Festuco pallenti-Brometum pannonici határán, É-i kitettségű dolomitsziklán. É.sz.: 47²7’ 32.4”; K.h.: 18²7’ 21.6”; Tszf.m.: kb. 295 m (GPS 558/1). Leg.: Németh, Cs., 2005.III.25. [BP 92216]. - Vértes: Vérteskozma, Nagy-Tábor-hegy, alt. ca. 350 m, Mercuriali-Tilietum. [Solymosi 1975, 1976]. Vértes: Vérteskozma (Fejér m.), Nagy-Tábor-hegy, Fago-Ornetum és Festuca pallenti-Brometum pannonici határán, É-i kitettségü dolomitsziklán. É.sz.: $47^{\circ} 26^{\prime}$ 55.8”; K.h.: $18^{\circ} 26^{\prime} 34.3^{\prime \prime}$; Tszf.m.: kb. 357 m (GPS 551/1). Leg.: Németh, Cs., 2005.03.25. [hb. Németh]. - Vértes, Fejér megye, Vérteskozma, Nagy-Tábor-hegy, Fago-Ornetum és Festuco pallenti-Brometum pannonici határán, É-i kitettségü dolomitsziklán. É.sz.: 47 26’ 51.0”; K.h.: $18^{\circ} 26^{\prime}$ 29.5”; Tszf.m.: kb. 357 m (GPS 551/1). Leg.: Németh, Cs., 2005.III.25. [BP 92217]. - Vértes, Fejér megye, Vérteskozma, Nagy-Tábor-hegy, Fago-Ornetum, É-i kitettségű dolomitsziklán. É.sz.: $47^{\circ} 26^{\prime}$ 51.0"; K.h.: $18^{\circ} 26^{\prime}$ 29.5"; Tszf.m.: kb. 361 m (GPS 549). Leg.: Németh, Cs., 2005. III.25. [BP 92218]. - Comit. Fejér. In rupibus dolom. silvat. vallis Svábrőzse-völgy prope Vérteskozma. Alt. s. met. ca: 340. Leg.: Boros, Á., 1935.04.07. [BP 36690, EGR 5643]. - Vértes, Fejér megye, Vérteskozma, Svábrőzse-völgy, É-ÉK-i kitettségű dolomitsziklán. É.sz.: $47^{\circ} 26^{\prime} 31.4^{\prime \prime}$; K.h.: 18² 27' 32.4”; Tszf.m.: kb. 361 m (GPS 584). Leg.: Németh, Cs., 2005.III.27. [BP 92219, hb. Németh]. - Comit. Komárom et Fejér. In silvis versus Vérteskozma prope Várgesztes. Alt. s. met. ca: 3-400. Leg.: Boros, Á., 1932.04.24. [BP 36705, EGR 5642].

\section{Excluded specimens}

Solorina bispora Nyl. - Hungary: Vértes, Vérteskozma, Széna-hegy, alt. ca. $290 \mathrm{~m}$, Mercuriali-Tilietum. [Solymosi 1975, 1976]. - Voucher specimen is not existing.

Solorina octospora Arn. - Hungary: Zemplén hg.: Telkibánya és Gunyakút közötti út mentén. Leg.: Verseghy, K., 1959.05.29. [BP 50549]. - Not a Solorina species.

\section{DISCUSSION}

The first Solorina saccata specimens in Hungary found $c a 100$ years ago by Gy. Timkó (1914) and Ö. Szatala $(1916,1918,1921)$ in the Buda and Pilis Mts (Nagy-Szénás, Ördög-orom, Hunyad-orom, Vaskapu) (Fig. 3) were reported by Szatala $(1925,1930)$ and Timkó $(1925)$.

One of the most fruitful early collector was Ádám Boros, the famous Hungarian botanist and bryologist, who practically explored most of the area of 
Hungary. He wrote travelling diaries on his field trips and also collected many vouchers. In several cases the remarkable lichens, mostly the macrolichens were included in his diaries. He preferred to record Solorina saccata from all localities where he found it, maybe because its similarity to the large thalloid liverwort species (e.g. Conocephalum, Lunularia, Marchantia or Pellia spp.), or most probably because he was just aware of its rarity and very few former floristical records. Altogether 48 specimens ( $c$ 25\%) (BP, EGR) were collected by him from several localities in the Bakony, Buda, Bükk and Vértes Mts between 1920 and 1962.

Several recent localities have been discovered in the Bakony Mts, Balaton Uplands, Keszthely Mts and Vértes Mts by Csaba Németh. Within this region all former localities discovered originally by Á. Boros were revisited also by him and it could be concluded that almost all former Solorina localities are still existing even 80-100 years later (Figs 4-5). He collected ca 50\% of the existing Solorina saccata specimens between 2002 and 2015.

Solorina saccata seems to have a more or less continuous distributional area from the Keszthely Mts to the Buda Mts, including also the Balaton Uplands, the Bakony, Vértes and Pilis Mts. It occurs also in the Bükk Mts and in the Aggtelek karst. It is missing from its potential habitats of the Mecsek and Villány Mts.

In Hungary Solorina saccata occurs in shaded, humid, rocky microhabitats (Fig. 6), dominantly on calcareous soil rich in humus, in cracks, crevices, fissures or ledges of north facing (dolomite or limestone) rock walls or outcrops together with mosses (VERSEGHY 1994).

In its typical habitats Solorina saccata is usually growing in the higher plant associations Fago-Ornetum, Mercuriali-Tilietum, Festuco pallenti-Brometum pannonici (in the Transdanubian Mountain Range), Seslerietum sadlerianae (in the Buda Mts) or Seslerietum heuflerianae-hungaricae (in the Northern Mountain Range) together with free-living algae (Trentepoblia sp.), other lichens (e.g. Gyalecta jenensis, Protoblastenia rupestris, also with Gyalecta leucaspis in the Bakony Mts) and bryophytes (Ctenidium molluscum, Distichium capillaceum, Neckera crispa), since they have similar ecological requirements. In the Transdanubian Mountain Range these habitats are usually bare rocky outcrops without or with less vascular plants, for example Hieracium baubinii, $H$. pilosella, Festuca pallens, Sedum sexangulare (between crevices of rocks), and Inula conyza.

These habitats can be influenced heavily by anthropogenic activities (disturbance, fragmentation, etc.), which might cause real risk for the effective protection of the species.

Phytocoenological relations, population dynamical conditions and habitat preferences of Solorina saccata are still in need to be studied more carefully, especially for conservational purposes. 

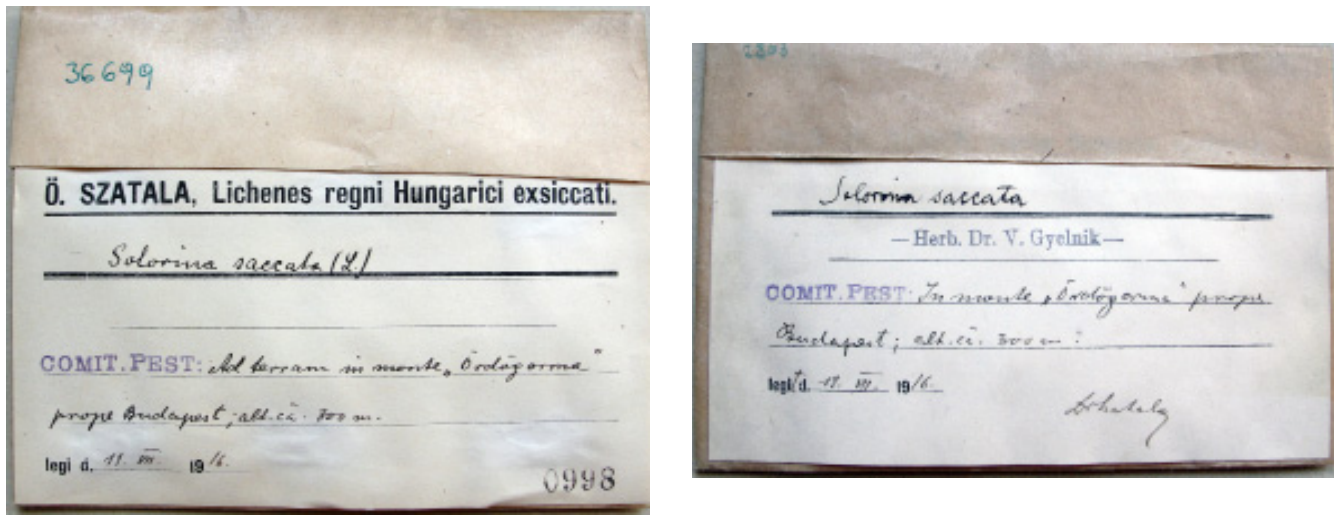

Fig. 3. The oldest Hungarian Solorina saccata specimens from the lichen collection of the Hungarian Natural History Museum (BP) (photo: Lőkös, L.).
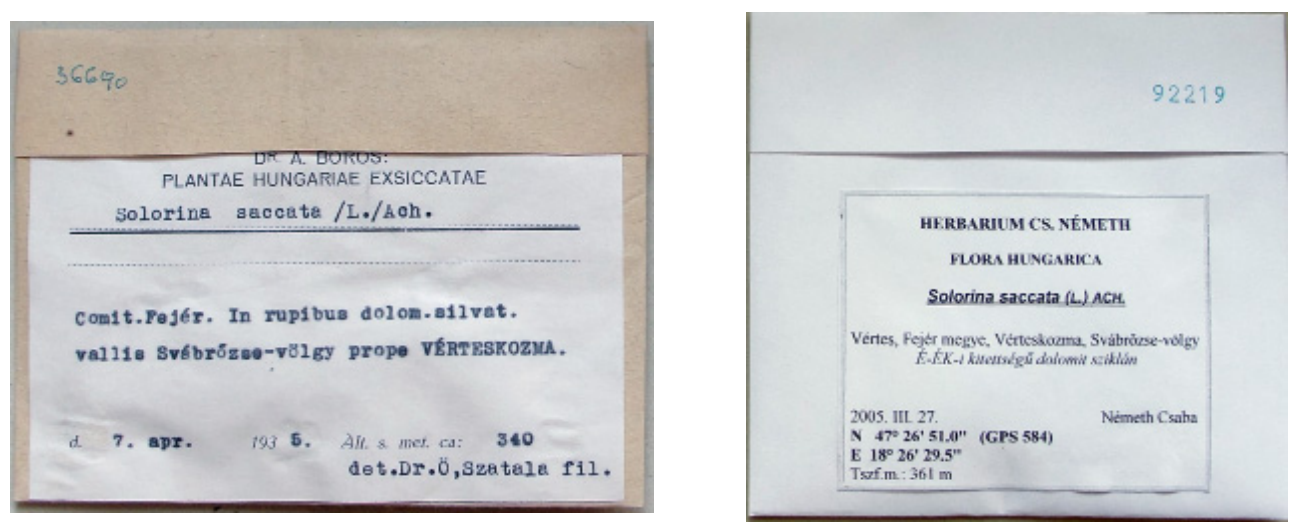

Fig. 4. Old specimen from 1935 (leg. Á. Boros) and a recent collection from the same place after $c a$ 80 years (leg. Cs. Németh) (photo: Lőkös, L.).
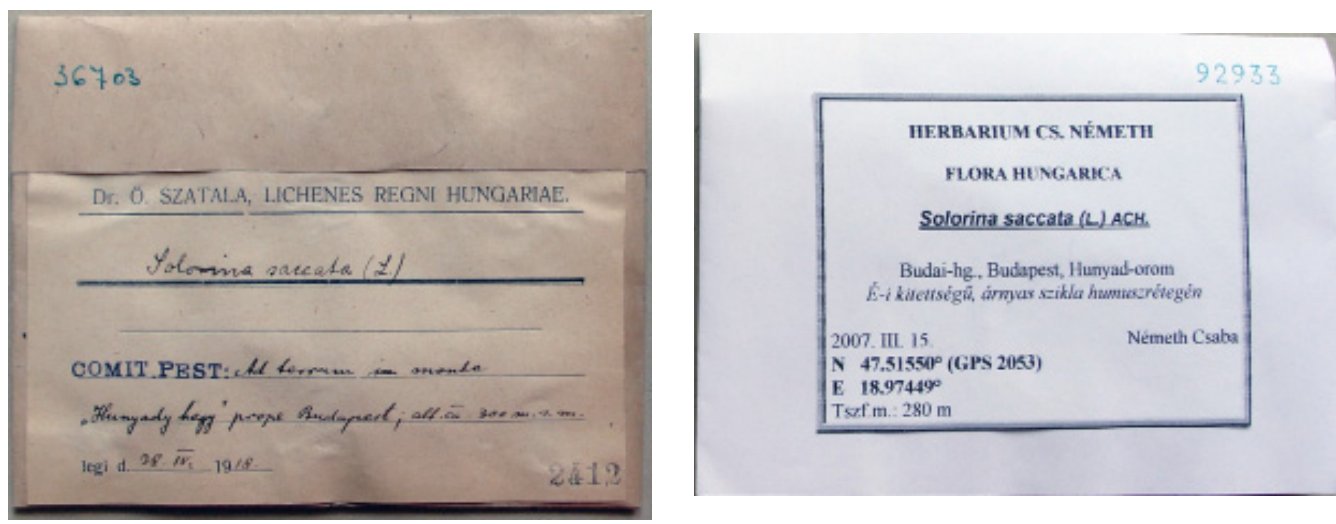

Fig. 5. Old specimen from 1918 (leg. Ö. Szatala) and a recent collection from the same place after 100 years (leg. Cs. Németh) (photo: Lőkös, L.). 

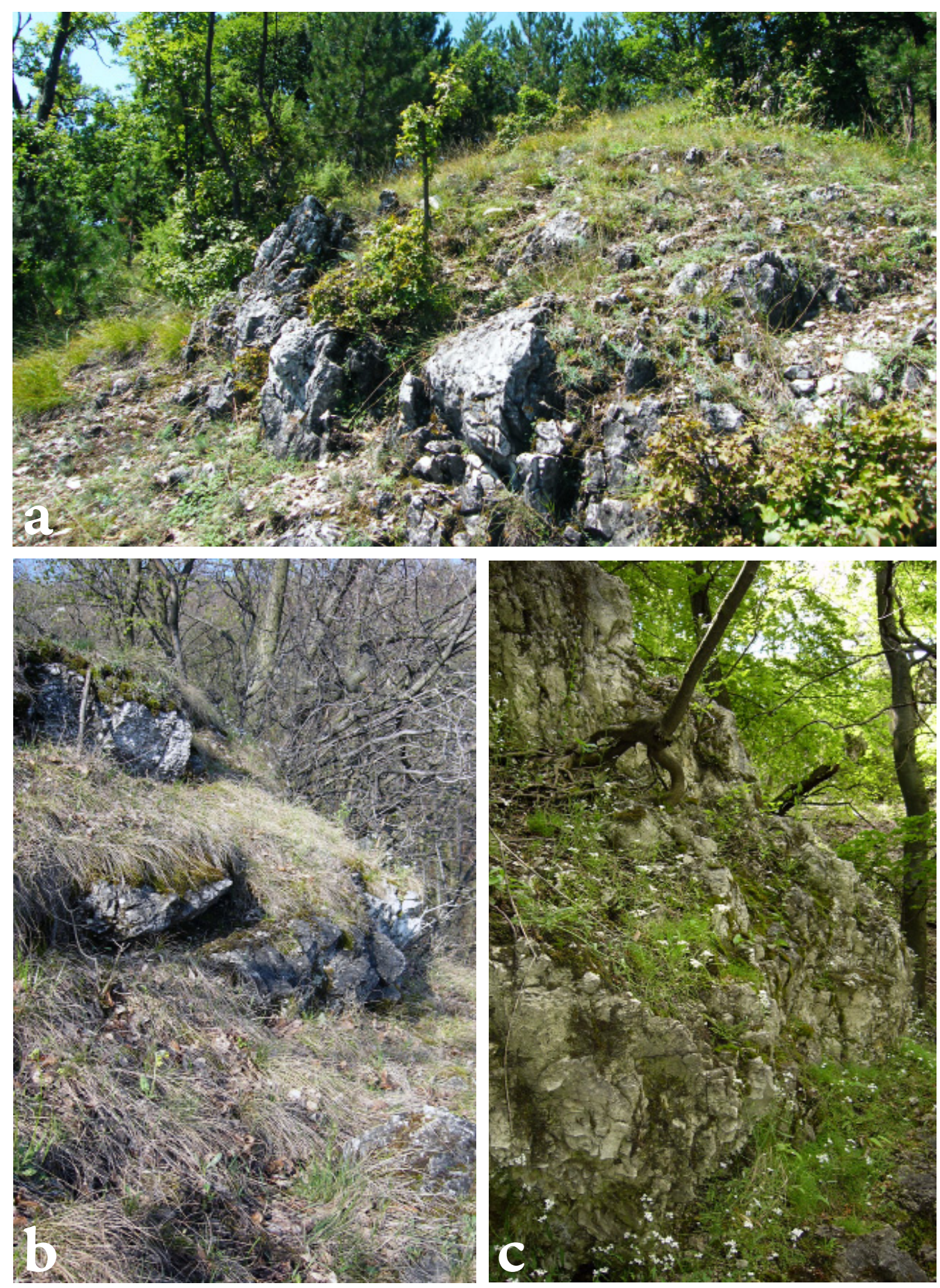

Fig. 6. Typical habitats for Solorina saccata in Hungary, a = rocky grassland in Fago-Ornetum (Sáska, Rosta-völgy, 29.07.2016) (photo: Sinigla, M.), b-c = rocky grasslands in the Vértes Mts, b = Gémförtés-völgy (16.04.2005), c = Fáni-völgy (17.05.2005) (photo: Németh Cs.). 
Acknowledgements - We are grateful to the national park directorates, who made our field works possible. Special thank to colleagues Zoltán Barina, Ildikó Békási, Nóra Békefi, Peter Erzberger, Anna Guttová, Andor Kovács, Gábor Mészáros, Zoltán Nagy, Beáta Papp, Rita Rezneki, Eszter Schuler, Lajos Somlyay and János Varga for their kind company in some field works, and to those who placed their collection to our disposal (Norbert Bauer, Beáta Papp, Lajos Somlyay). The work was supported by the project NKFI K124341.

Összefoglaló: A pettyegetett tárcsalapony (Solorina saccata) 1997-ben veszélyeztetett státuszt, majd 2013-ban törvényes oltalmat kapott Magyarországon. A mintegy 200 régi és újabb, lelőhelyi és irodalmi adat alapján közel 100 lelőhelyét igazoltuk az Aggteleki-karszt (1), a Bakony (29), a Balaton-felvidék (5), a Budai-hegység (8), a Bükk (7), a Gerecse (6), a Keszthelyi-hegység (10), a Kőszegi-hegység (2), a Pilis (2) és a Vértes (30) területéről. A nemzetség két további fajának ( $S$. bispora, $S$. octospora) publikált, valamint herbáriumi adaton alapuló hazai előfordulását nem sikerült igazolnunk, illetve megerősítenünk. A szakirodalmi és herbáriumi források alapján elkészítettük a pettyegetett tárcsalapony aktuális magyarországi elterjedési térképét, a legtöbb régi lelőhely felkeresésével megpróbáltunk további információkat gyűjteni a még létező populációinak állapotáról a természetvédelem számára. Míg a Dunántúli-középhegység térségében viszonylag elterjedt, a Mecsekben és a Villányi-hegységben eddig nem sikerült megtalálni a potenciális élőhelyeken. Az utóbbi évtizedekben a faj Európa számos országában visszahúzódó tendenciát mutat, hazánkban elsősorban az alkalmas élőhelyek fragmentálódása, elpusztulása jelenthet kockázati tényezőt. További élőhely-preferencia és populációdinamikai vizsgálatok alapvető fontosságúak a konzervációbiológiai igények tisztázásához, a védettség szakszerű és hatékony biztosításához.

\section{REFERENCES}

Abolina, A., Piterāns, A. and Bambe, B. (2015): Lichens and bryophytes in Latvia: checklist. Daugavpils Univ. Akad. apg. "Saule”, Latvijas Valsts mež. inst. "Silava”, Latvia, 213 pp.

Aptroot, A., van Herk, C. M., Sparrius, L. B. and Spier, J. L. (2004): Checklist van de Nederlandse korstmossen en korstmosparasieten. [Checklist of the lichens and lichenicolous fungi of the Netherlands]. - Buxbaumiella 69: 17-55.

BesCHEL, R. (1958): Flechtenvereine der Städte, Stadtflechten und ihr Wachstum. - Ber. Naturwiss.Med. Ver. in Innsbruck 52: 1-158.

Bilovitz, P. O. and MAYrhofer, H. (2011): Catalogue of the lichenized and lichenicolous fungi of Bosnia and Herzegovina. - Phyton (Austria) 51(1): 1-67.

Boros, Á. (1933): A Primula auricula a Vértes-hegységben. - Bot. Közlem. 30(5): 189-191.

Boros, Á. (1944): Adatok a Budai hegység moháinak ismeretéhez. (Beiträge zur Kenntnis der Moosflora der Budaer Berge. Umgebung von Budapest). - Bot. Közlem. 41(3-5): 153-154.

Boros, Á. (1963): Die Steppenflechten. - Die Pyramide (Innsbruck) 11(2): 59-61.

Burgaz, A. R. and Martínez, I. (1998): Estudio del género Solorina Ach. (Ascomicetes liquenizados) en la Península Ibérica. [Study of the genus Solorina Ach. (lichenized Ascomycetes)]. Bot. Complutensis 22: 63-73.

Burgaz, A. R. and Martínez, I. (2003): Flora Liquenológica Ibérica. Peltigerales: Lobariaceae, Nephromataceae, Peltigeraceae. - Sociedad Española de Liquenología (SEL), Murcia, 61 pp.

Ciurchea, M. (2004): Determinatorul lichenilor din România. - Editura BIT, Iaşi, 488 pp.

Clerc, P. and Truong, C. (2012): Catalogue des lichens de Suisse. - http://www.ville-ge.ch/musinfo/bd/cjb/cataloguelichen [Version 2.0, 11.06.2012]. 
DiEDERICH, P. and SÉRUSIAUX, E. (2000): The lichens and lichenicolous fungi of Belgium and Luxembourg. An annotated checklist. - Musée National d'Histoire Naturelle, Luxembourg, 208 pp.

FaŁtynowicz, W. (1993): A checklist of Polish lichen forming and lichenicolous fungi including parasitic and saprophytic fungi occurring on lichens. - Polish Bot. Studies 6: 1-65.

Faetrynowicz, W. and Kossows Ka, M. (2016): The lichens of Poland: a fourth checklist. - Acta Bot. Silesiaca, Monogr. 8: 3-122.

FARKAS, E. (1990): Lichenológiai vizsgálatok Budapesten és a Pilis Bioszféra Rezervátumban - elterjedés, bioindikáció. (Investigation of the lichen flora in Budapest and in the Pilis Biosphere Reservation - distribution and bioindication. (In Hungarian)). - Kand. dissz., Vácrátót, 121 $+30 \mathrm{pp}$.

Farkas, E., Lökös, L., Sinigla, M. and Varga, N. (2014): A Mogyorós-hegy (Litér) és az Ugrihegy (Királyszentistván) zuzmóflórája. (The lichen flora of the hills "Mogyorós-hegy" (Litér, Hungary) and "Ugri-hegy" (Királyszentistván, Hungary)). - Folia Mus. Hist-nat. Bakony. 31 : 7-24.

Fekete, G., Majer, A., Tallós, P., Vida, G. and Zólyomi, B. (1961): Angaben und Bemerkungen zur Flora und zur Pflanzengeographie des Bakonygebirges. - Annls hist.-nat. Mus. natn. Hung. 53: 241-253.

GALLÉ, L. (1961): Újabb adatok Keszthely és környékének zuzmóflórájához. (Neuere Angaben über die Flechtenflora von Keszthely und Umgebung). - Bot. Közlem. 49(1-2): 84-94.

GALlÉ, L. (1973): A Balaton-menti dolomitvonulat zuzmócönózisai. - Veszpr. Megy. Múz. Közlem. 1973: $183-190$.

GALLÉ, L. (1977): Magyarország zuzmócönózisai. (Flechtenassoziationen in Ungarn). - Móra F. Múz. Évk. 1976-77: 429-493.

GILBERT, O. L. (1975): Distribution maps of lichens in Britain. - Lichenologist 7: 180-192. https://doi.org/10.1017/s0024282975000266

Guttová, A., LAckovicová, A. and Pišút, I. (2013): Revised and updated checklist of lichens of Slovakia (May 2013). - Biologia 68(5): 845-850. https://doi.org/10.2478/s11756-013-0218-y

HAFEllner, J. (2007): Checklist and bibliography of lichenized and lichenicolous fungi so far reported from Albania (version 05-2007). - Fritschiana 59: 1-18.

HAFEllner, J. and TÜRK, R. (2001): Die lichenisierten Pilze Österreichs - eine checkliste der bisher nachgewiesenen Arten mit verbreitungsangaben. - Stapfia 76: 1-167.

HAfellner, J. and Türk, R. (2016): Die lichenisierten Pilze Österreichs - eine neue checkliste der bisher nachgewiesenen taxa mit angaben zu verbreitung und substratökologie. (The lichenized fungi of Austria - a new checklist of the taxa so far recorded, with data to distribution and substrate ecology). - Stapfia 104(1): 1-216.

Kiszelyné-VÁmosi, A., Marschall, Z., Orbán, S. and Suba, J. (1989): A Bükk hegység északi peremhegyeinek florisztikai és cönológiai jellemzése. - Acta Acad. Paed. Agriensis, n. s. XIX(VI): 135-185.

Klement, O. (1955): Prodromus der mitteleuropaischen Flechtengesellschaften. - Feddes Repert. Beih. 135: 5-194.

KNEŽEVIĆ, B. and MAYRHOFER, H. (2009): Catalogue of the lichenized and lichenicolous fungi of Montenegro. - Phyton 48(2): 283-328.

Kondratyuk, S. Y., Khodosovtsev, A. Y. and Zelenko, S. D. (1998): The second checklist of lichen-forming, lichenicolous and allied fungi of Ukraine. - M. H. Kholodny Institute of Botany, Kiev, 179 pp.

LišKa, J., PALICE, Z. and Slaví KovÁ, Š. (2008): Checklist and red list of lichens of the Czech Republic. - Preslia 80: 151-182. 
Llimona, X. and Hladun, N. L. (2001): Checklist of the lichens and lichenicolous fungi of the Iberian Peninsula and Balearic Islands. - Bocconea 14: 1-581.

Lö Kös, L. (2009): The lichen-forming fungi of the Aggtelek National Park (NE Hungary). - In: PAPP, B. (ed.): Flora of the Aggtelek National Park. Cryptogams. Hungarian Natural History Museum, Budapest, 109-174 pp.

LöKös, L. (2010): A Naszály zuzmóflórája. (The lichen flora of Mt Naszály (Hungary)). - In: PiNTÉR, B. \& TímÁr, G. (eds): A Naszály természetrajza. Tanulmánygyüjtemény. (A natural history of Mt Naszály, Hungary). - Rosalia 5: 109-159.

Löкӧs, L. and Tóтн, E. (1997): Red list of lichens of Hungary (a proposal). - In: Tóтн, E. and Horvát H, R. (eds): Proceedings of the "Research, Conservation, Management" Conference, Aggtelek, Hungary, 1-5 May 1996, Volume I, pp. 337-343.

Lőkös, L., Tótн, Z. and BALOGH, L. (1997): A Köszegi-hegység zuzmóflórája. - Tilia 5: 7-91.

MARSTALler, R. (1994): Zur Verbreitung bemerkenswerter Moose in der Umgebung von Budapest (Ungarn). - Feddes Repert. 105(7-8): 531-547. https://doi.org/10.1002/fedr.4921050718

Marstaller, R. (1996): Die Bryophyten-Gesellschaften des Verbandes Ctenidion mollusci Ştef. 1941 in der Umgebung von Budapest (Ungarn). (Bryophyte communities of the alliance Ctenidion mollusci Ştef. 1941 in the surroundings of Budapest (Hungary)). - Tuexenia 16: 553-578.

Martínez, I. and Burgaz, A. R. (1998): Revision of the genus Solorina (Lichenes) in Europe based on spore size variation. - Ann. Bot. Fennici 35: 137-142.

Mayrhofer, H., Rohrer, A. and Bilovitz, P. O. (2013): Catalogue of the lichenized and lichenicolous fungi of Macedonia (FYROM). - Phyton 53(1): 23-72.

Mayrhofer, H., Czeh, D., Kobald, E. M. and Bilovitz, P. O. (2016): Catalogue of the lichenized and lichenicolous fungi of Kosovo. - Herzogia 29(2): 529-554.

https://doi.org/10.13158/heia.29.2.2016.529

Mayrhofer, H., Denchev, C. M., Stoykov, D. Y. and Ni kolova, S. O. (2005): Catalogue of the lichenized and lichenicolous fungi in Bulgaria. - Mycol. Balcanica 2(1): 3-61.

Mirek, Z., Zarzycki, K., Wojewoda, W. and SzeląG, Z. (2006): Red list of plants and fungi in Poland. (Czerwona lista roślin i grzybów Polski). - W. Szafer Institute of Botany, Polish Academy of Sciences, Kraków, 100 pp.

MK (2013): 83/2013. (IX. 25.) VM rendelet. A védett és a fokozottan védett növény- és állatfajokról, a fokozottan védett barlangok köréről, valamint az Európai Közösségben természetvédelmi szempontból jelentős növény- és állatfajok közzétételéről szóló 13/2001. (V. 9.) KöM rendelet módosításáról. - Magyar Közlöny 2013(156): 67479-67503. (2013. szeptember 25).

MolnáR, K. and LöKös, L. (2007): Adatok az Upponyi-szoros zuzmóflórájához. (Contributions to the lichen flora of the Upponyi-szoros). - Folia nat.-hist. Mus. Matrensis 30: 25-34. (2006).

Motiejūnaité, J. (2017): Supplemented checklist of lichens and allied fungi of Lithuania. - Bot. Lith. 23(2): 89-106. https://doi.org/10.1515/botlit-2017-0011

NikLfELd, H. (1971): Bericht über die Kartierung der Flora Mitteleuropas. - Taxon 20: 545-571. https://doi.org/10.2307/1218258

Nimis, P. L. (2016): The lichens of Italy. A second annotated catalogue. - EUT, Edizioni Universita di Trieste, Trieste, $740 \mathrm{pp}$.

Polgár, S. (1933): A Bakonyi Tobánhegy vegetációja. - Bot. Közlem. 30: 32-47.

RANDLANE, T. and SAAG, A. (eds) (1999): Second checklist of lichenized, lichenicolous and allied fungi of Estonia. - Folia Cryptog. Estonica 35: 1-132.

Randlane, T., JÜriado, I., SuIJA, A., Lôhmus, P. and LEPPIK, E. (2008): Lichens in the new red list of Estonia. - Folia Cryptog. Estonica 44: 113-120. 
Reimers, H. (1940): Bemerkenswerte Moos-und Flechtengesellschaften auf Zechstein-Gips am Südrande des Kyffhäusers und des Harzes. - Hedwigia 79: 81-174.

Roux, C. et coll. (2017): Catalogue des lichens et champignons lichénicoles de France métropolitaine. 2e édition revue et augmentée (2017). - Édit. Association française de lichénologie (A. F. L.), Fontainebleau, $1581 \mathrm{pp}$.

Santesson, R., Moberg, R., Nordin, A., Tønsberg, T. and Vitikainen, O. (2004): Lichenforming and lichenicolous fungi of Fennoscandia. - Museum of Evolution, Uppsala University, Uppsala, Sweden, 359 pp.

SAvić, S. and Tibell, L. (2006): Checklist of the lichens of Serbia. - Mycol. Balcan. 3: 187-215.

SCheidegger, C. and Clerc, P. (2002): Liste Rouge des espèces menacées en Suisse: Lichens épiphytes et terricoles. - Ed. Office fédéral de l'environnement, des foręts et du paysage OFEFP, Berne, Institut fédéral de recherches WSL, Birmensdorf, et Conservatoire et Jardin botaniques de la Ville de Genève, CJBG. OFEFP - Série: L’environnement pratique, $124 \mathrm{pp}$.

SEAWARD, M. R. D. (1984): Census catalogue of Irish lichens. - Glasra 8: 1-32.

SEAWARD, M. R. D. (1994): Vice-county distribution of Irish lichens. - Biol. Environm.: Proceeds Royal Irish Acad. 94B(2): 177-194.

Simon, T., Horánszky, A., J. Komlódi, M., K. LÁng, E. and M. Draskovits, R. (1976): Növényrendszertani terepgyakorlatok. - Tankönyvkiadó, Budapest, 140 pp.

Smith, C. W., Aptroot, A., Coppins, B. J., Fletcher, A., Gilbert, O. L., James, P. W. and Wolseley, P. A. (eds) (2009): The lichens of Great Britain and Ireland. - British Lichen Society, London, $1046 \mathrm{pp}$.

Søchting, U. and Alstrup, V. (2008): Danish lichen checklist, Version 2. - Botanical Institute, University of Copenhagen, Copenhagen, $46 \mathrm{pp}$.

Solymosi, P. (1975): A Vértes hegység zuzmóflórája. - Bot. Közlem. 62(3): 191-196.

Solymosi, P. (1976): Die Flechten des Vértes-Gebirges in Ungarn. - Herzogia 4: 209-212.

Solymosi, P. (1979): A Gerecse-hegység zuzmói. (Über den Flechten im Gerecse-Gebirge). - Bot. Közlem. 66(3): 185-194.

Stenroos, S., Velmala, S., Pykala, J. and Ahti, T. (eds) (2016): Lichens of Finland. - Norrlinia 30: 1-896.

SupPAN, U., Prügger, J. and MAYrhofer, H. (2000): Catalogue of the lichenized and lichenicolous fungi of Slovenia. - Bibl. Lichenol. 76: 1-215.

SzATAla, Ö. (1925): Adatok Magyarország zuzmóflórájának ismeretéhez. (Beiträge zur Kenntnis der Flechtenflora Ungarns). - Magyar Bot. Lapok 24: 43-75.

Szatala, Ö. (1930): Lichenes Hungariae. Magyarország zuzmóflórája. II. Gymnocarpeae (Graphidineae, Cyclocarpineae: Lecanactidaceae - Peltigeraceae). - Folia Cryptog. I(7): 833-928.

Thiers, B. (2014, continuously updated): Index Herbariorum: a global directory of public herbaria and associated staff. - New York Botanical Garden's Virtual Herbarium. http://sweetgum. nybg.org/ih/.

Timkó, Gy. (1925): Új adatok a Budai és Szentendre-Visegrádi hegyvidék zuzmóvegetációjának ismeretéhez. (Neue Beiträge zur Kenntnis der Flechtenvegetation des Buda-SzentendreVisegráder Gebirges). - Bot. Közlem. 22: 81-104. (1924-25). (30)-(31).

TÜRK, R. and HAFELLNER, J. (1999): Flechten. Rote liste gefährdeter Flechten (Lichenes) Österreichs. 2. Fassung. - In: Niklfeld, H. (ed.): Rote Listen gefährdeter Pflanzen Österreichs. Grüne Reihe des Bundesministeriums für Umwelt, Jugend und Familie, Austria Medien Service, Graz, Band 10, pp. 187-228.

Verseghy, K. (1973): Az Északi- és a Keleti-Bakony zuzmóvegetációja. (Die Flechten-Vegetation des Nord- und Ost-Bakony-Gebirges). - Veszprém Megy. Múz. Közlem. 12: 169-182. 
Verseghy, K. (1994): Magyarország zuzmóflórájának kézikönyve. (The lichen flora of Hungary). Magyar Természettudományi Múzeum, Budapest, 415 pp.

VIDA, G. (1956): Adatok a Köszegi-hegység vegetációjáboz. - TDK dolgozat, Budapest.

Vitikainen, O. (2007): Solorina Ach. - In: Nordic Lichen Flora. Vol. 3. Cyanolichens. The Nordic Lichen Society, Museum of Evolution, Uppsala University, Uppsala, pp. 129-131.

Wirth, V., Hauck, M. and Schultz, M. (2013): Die Flechten Deutschlands. - Verlag Eugen Ulmer, Stuttgart, $1144 \mathrm{pp}$.

Wirth, V., Hauck, M., von Brackel, W., Cezanne, R., de Bruyn, U., Dürhammer, O., EichLer, M., GnüChtel, A., John, V., Litterski, B., Otte, V., Schiefelbein, U., SCholz, P., Schultz, M., Stordeur, R., Feuerer, T. and Heinrich, D. (2011): Rote Liste und Artenverzeichnis der Flechten und flechtenbewohnenden Pilze Deutschlands. [Red list and checklist of species of lichens and lichenicolous fungi of Germany]. - Naturschutz und Biologische Vielfalt 70(6): 7-122.

Woods, R. G. and Coppins, B. J. (2012): A conservation evaluation of British lichens and lichenicolous fungi. Species Status 13. - Joint Nature Conservation Committee, Peterborough, 155 pp.

Zólyomi, B. (1936): A pannóniai flóratartomány és az északnyugatnak határos területek sziklanövényzetének áttekintése. (Übersicht der Felsenvegetation in der Pannonischen Florenprovinz und dem nordwestlich angrenzenden Gebiete). - Ann. Mus. Nat. Hung., Pars Bot. 30: $136-174$.

Zólyomi, B. (1950): Фитоценозы и месомелиорации обнажений гор Буды. (Les phytocenoses des montagnes de Buda et le reboisement des endroits dénudés). - Acta Biol. Acad. Sci. Hung. 1: 7-67.

Zólyomi, B. (1958): Budapest és környékének természetes növénytakarója. - In: PÉcsi, M., MARosi, S. and SzILÁRD, J. (eds): Budapest természeti képe. Akadémiai Kiadó, Budapest, pp. 511-644.

ArtDatabanken, Swedish Species Information Centre, Uppsala. - https://www.artdatabanken.se/ en/; http://artfakta.artdatabanken.se/

Artsdatabanken, Norwegian red list for species. - Norwegian Biodiversity Information Centre (NBIC), Trondheim, https://artsdatabanken.no/Rodliste

(submitted: 30.03.2018, accepted: 01.06.2018) 